\title{
Distinct Neurochemical and Functional Properties of GAD67-Containing 5-HT Neurons in the Rat Dorsal Raphe Nucleus
}

\author{
Hiroki Shikanai, ${ }^{1}$ Takayuki Yoshida, ${ }^{1}$ Kohtarou Konno, ${ }^{2}$ Miwako Yamasaki, ${ }^{2}$ Takeshi Izumi, ${ }^{1}$ Yu Ohmura, ${ }^{1}$ \\ Masahiko Watanabe, ${ }^{2}$ Mitsuhiro Yoshioka ${ }^{1}$ \\ Departments of ${ }^{1}$ Neuropharmacology and ${ }^{2}$ Anatomy, Hokkaido University Graduate School of Medicine, Sapporo 060-8638, Japan
}

\begin{abstract}
The serotonergic (5-HTergic) system arising from the dorsal raphe nucleus (DRN) is implicated in various physiological and behavioral processes, including stress responses. The DRN is comprised of several subnuclei, serving specific functions with distinct afferent and efferent connections. Furthermore, subsets of 5-HTergic neurons are known to coexpress other transmitters, including GABA, glutamate, or neuropeptides, thereby generating further heterogeneity. However, despite the growing evidence for functional variations among DRN subnuclei, relatively little is known about how they map onto neurochemical diversity of 5-HTergic neurons. In the present study, we characterized functional properties of GAD67-expressing 5-HTergic neurons (5-HT/GAD67 neurons) in the rat DRN, and compared with those of neurons expressing 5-HTergic molecules (5-HT neurons) or GAD67 alone. While 5-HT/GAD67 neurons were absent in the dorsomedial (DRD) or ventromedial (DRV) parts of the DRN, they were selectively distributed in the lateral wing of the DRN (DRL), constituting $12 \%$ of the total DRL neurons. They expressed plasmalemmal GABA transporter 1, but lacked vesicular inhibitory amino acid transporter. By using whole-cell patch-clamp recording, we found that 5-HT/GAD67 neurons had lower input resistance and firing frequency than 5-HT neurons. As revealed by c-Fos immunohistochemistry, neurons in the DRL, particularly 5-HT/GAD67 neurons, showed higher responsiveness to exposure to an open field arena than those in the DRD and DRV. By contrast, exposure to contextual fear conditioning stress showed no such regional differences. These findings indicate that 5-HT/GAD67 neurons constitute a unique neuronal population with distinctive neurochemical and electrophysiological properties and high responsiveness to innocuous stressor.
\end{abstract}

\section{Introduction}

Serotonin (5-HT) exerts a tonic modulatory effect on a wide variety of physiological and behavioral processes (Lucki, 1998). 5-HT-producing neurons in the dorsal raphe nucleus (DRN) provide the majority of 5-HT innervations mainly to lateral forebrain areas, such as the basal ganglia, amygdala, and prefrontal cortex (Jacobs and Azmitia, 1992). Activation of 5-HTergic neurons in the DRN facilitates learned defensive behaviors (Zangrossi et al., 2001), while their inhibition by microinjection of GABA or benzodiazepine chlordiazepoxide exerts anxiolytic effects that attenuate suppression of conditioned punishing stimulus on lever-pressing behavior (Thiébot et al., 1980). Thus, 5-HT released from DRN neurons plays an important role in the regulation of anxiety responses.

Although the DRN is defined as a single nucleus, it is composed of subregions, which are clusters of neurons with distinct

\footnotetext{
Received Nov. 29, 2011; revised Aug. 20, 2012; accepted Aug. 21, 2012.

Author contributions: H.S. and T.Y. designed research; H.S., T.Y., and K.K. performed research; H.S. and K.K. analyzed data; H.S., T.Y., M. Yamasaki, T.I., Y.O., M.W., and M. Yoshioka wrote the paper.

This work was supported by Grant-in-Aid for Scientific Research 20390309 (M. Yoshioka) and the Strategic Research Program for Brain Sciences (Integrated Research on Neuropsychiatric Disorders; M. Yoshioka, M.W.) from the Ministry of Education, Culture, Sports, Science and Technology of Japan.

Correspondence should be addressed to Takayuki Yoshida, Department of Neuropharmacology, Hokkaido University School of Medicine, Sapporo 060-8638, Japan. E-mail tyoshida@med.hokudai.ac.jp.

DOI:10.1523/JNEUROSCI.5929-11.2012

Copyright $\odot 2012$ the authors $\quad 0270-6474 / 12 / 3214415-12 \$ 15.00 / 0$
}

morphological features (Jacobs and Azmitia, 1992). They are organized into two main rostrocaudal subdivisions and further divided into six subnuclei: rostral, caudal, interfascicular, dorsomedial (DRD), ventromedial (DRV), and lateral "wing" (DRL) parts. They are topographically organized so that neurons in respective subnuclei innervate distinct targets and receive discrete afferent inputs (Jacobs and Azmitia, 1992). Importantly, these anatomically distinct subnuclei show differential responsiveness to various stressors (Hale and Lowry, 2011), suggesting that changes in neuronal activity of a limited subset of 5-HTergic neurons may have important implications in specific physiological and behavioral responses. Moreover, subpopulations of 5-HTergic neurons differently coexpress neuropeptides and transmitters, generating further complexity within topographically organized subnuclei (Jacobs and Azmitia, 1992; Michelsen et al., 2007). Accordingly, despite the growing evidence for rostral-caudal and dorsal-ventral variations in DRN responses, relatively little is known about correlation with unique neurochemical properties of 5-HTergic neurons.

The firing activity of 5-HTergic neurons in the DRN is controlled by two main mechanisms, i.e., autoregulatory influences arising from 5-HTergic neurons themselves and heteroregulation by local neurons and afferents, including GABAergic, glutamatergic, and dopaminergic inputs (Piñeyro and Blier, 1999). Of these, GABAergic and 5-HTergic transmissions can negatively regulate 5-HT release (Gallager and Aghajanian, 1976; Piñeyro and Blier, 1999), and are thereby considered possible targets of 
therapeutic interventions. Interestingly, some 5-HTergic neurons have been shown to express GABA or its synthetic enzyme glutamic acid decarboxylase (GAD) (Nanopoulos et al., 1982; Belin et al., 1983; Fu et al., 2010; Hioki et al., 2010), suggesting a possible corelease of 5-HT and GABA. In this regard, these neurons may have a unique mechanism that controls their firing activity through autoregulatory feedback inhibition. However, functional properties of these neurons in the DRN remain largely unexplored.

In the present study, we characterized GAD67-expressing 5-HTergic neurons (5-HT/GAD67 neurons) in the DRN. We found that 5-HT/GAD67 neurons are localized to the DRL, constituting a unique neuronal population with distinct neurochemical and electrophysiological properties. Furthermore, these neurons show high responsiveness to innocuous stress compared with 5-HTergic neurons lacking GAD67 (5-HT neurons) and GAD67-expressing neurons lacking 5-HTergic markers (GAD67 neurons).

\section{Materials and Methods}

Animal. The first-breeder Wistar/ST rats were purchased from Nippon SLC and bred in our laboratory. Male rats at 3-4 weeks of age were used for analysis unless noted otherwise. Rats were group housed in a room with a $12 \mathrm{~h}$ light/dark cycle (with lights on at 7:00 P.M.) and a temperature-controlled environment $\left(22 \pm 1^{\circ} \mathrm{C}\right)$ with food and water $\mathrm{ad}$ libitum. All animals were treated in accordance with the guidelines for the Care and Use of Laboratory Animals of the Animal Research Committee of the Hokkaido University.

Drug. Diazepam (0.1 or $0.5 \mathrm{mg} / \mathrm{kg}$; Wako Pure Chemical Industries) suspended in $0.9 \%$ saline containing $1 \%$ arabic gum (Nacalai Tesque) was injected intraperitoneally.

Immunohistochemistry. Rats were anesthetized with sodium pentobarbital $(60 \mathrm{mg} / \mathrm{kg}$, i.p.) and transcardially perfused via the left ventricle with $0.9 \%$ saline followed by $4 \%$ paraformaldehyde in $0.1 \mathrm{M}$ sodium phosphate buffer (PB), pH 7.2. After removal from the skull, brains were immersed overnight in the same fixative at $4^{\circ} \mathrm{C}$, placed in $0.1 \mathrm{M} \mathrm{PB}$ containing $10-30 \%$ sucrose at $4^{\circ} \mathrm{C}$, and sectioned at $30 \mu \mathrm{m}$ thickness in a Leica HM 300 cryostat. Sections were collected in 0.01 м PBS, pH 7.2, containing $0.1 \%$ Triton X-100 (PBSTx) and stored for at least $1 \mathrm{~h}$ before immunohistochemical staining. All immunohistochemical incubations were done at room temperature. For immunofluorescence, sections were washed three times in PBSTx between incubations. Sections were incubated successively with $10 \%$ normal donkey serum for $20 \mathrm{~min}$ and a mixture of primary antibodies overnight: mouse anti-GAD67 (1:2000; MAB5406, Millipore Bioscience Research Reagents), goat anti-5-HT transporter (HTT) (Somogyi et al., 2004), rabbit anti-c-Fos (1:20,000; PC38T, Calbiochem), mouse anti-tryptophan hydroxylase (TPH; 1:2000; T0678, Sigma-Aldrich), guinea pig anti-parvalbumin (PV) (Nakamura et al., 2004), guinea pig anti-vesicular inhibitory amino acid transporter (VIAAT; $1 \mu \mathrm{g} / \mathrm{ml}$ ) (Miyazaki et al., 2003; Miura et al., 2006), and rabbit anti-GABA transporter-1 (GAT-1; 1:1000; AB1570, Millipore Bioscience Research Reagents) antibodies. Then they were incubated with a mixture of fluorophore-linked species-specific secondary antibodies, Alexa 488 and Alexa 647 (Invitrogen), and indocarbocyanine (Cy3; Jackson ImmunoResearch) at a dilution of 1:200 for $1 \mathrm{~h}$. Image were taken with a confocal laser-scanning microscope FV1000 or FV-10i (Olympus). To avoid cross talk between multiple fluorophores, Alexa $488, \mathrm{Cy} 3$, and Alexa 647 fluorescent signals were acquired sequentially using the 488, 543, and $633 \mathrm{~nm}$ excitation laser lines, respectively. All images show single optical sections $(640 \times 640$ pixels; pixel size, $110 \mathrm{~nm})$.

Immunoperoxidase for c-Fos was performed by using the avidin-biotin immunoperoxidase technique. After incubation in PBS and normal goat serum, sections were successively incubated with c-Fos antibody for $48 \mathrm{~h}$, biotinylated goat anti-rabbit IgG (Vector Laboratories) for $1 \mathrm{~h}$, and avidin-biotinylated horseradish peroxidase complex (Vectastain Elite ABC Kit, Vector Laboratories) for $1 \mathrm{~h}$. Immunoreaction was visualized by trans-
Table 1. The primer sequences and estimated product lengths for single-cell RT-PCR

\begin{tabular}{llc}
\hline Gene & Sequence & Product length (bp) \\
\hline TPH2 & Forward: 5'-TACGGCACCGAGCTTGAC-3' & 84 \\
& Reverse: 5'-TGGCCACATCCACCAAATAC-3' & \\
GAD67 & Forward: 5'-CAAGTTCTGGCTGATGTGGA-3' & 231 \\
& Reverse: 5'-GCCACCCTGTGTAGCTTTTC-3' & \\
NSE & Forward: 5'-ATAGTGGGGGATGACCTGAC-3' & 200 \\
& Reverse: 5'-ATGAACGTGTCCTCCGTTC-3' & \\
VIAAT & Forward: 5'-GGGCTGGAACGTGACAAA-3' & 65 \\
& Reverse: 5'-GGAGGATGGGGTAGGGTAG-3' & \\
\hline
\end{tabular}

Primer sequences and estimated product lengths for RT-PCR are shown. The primers are used for both the first and second PCR amplifications. The concentration of the primers is $1 \mu \mathrm{m}$ for the first $\mathrm{PCR}$ and $10 \mu \mathrm{m}$ for the second $P C R$.

ferring the sections to $50 \mathrm{~mm}$ Tris- $\mathrm{HCl}$ buffer, $\mathrm{pH}$ 7.6, containing $0.05 \%$ diaminobenzidine, $0.6 \%$ nickel ammonium sulfate, and $0.01 \% \mathrm{H}_{2} \mathrm{O}_{2}$.

Fluorescent in situ hybridization. Procedures for double fluorescent in situ hybridization (FISH) labeling were reported previously (Yamasaki et al., 2010). To fresh frozen sections we applied $\sim 300 \mathrm{ng} / \mathrm{ml}$ of fluoresceinor digoxigenin (DIG)-labeled riboprobes that were antisense to cDNAs of mouse GAD67 (nucleotide residues 1036-2015; GenBank accession number NM_008077), TPH2 (nucleotide residues 1-1000; GenBank accession number NM_173391.3), and GAT-1 (nucleotide residues 3802179; GenBank accession number NM_178703). DIG and fluorescein were detected by the two-step method: the first detection was with peroxidase-conjugated anti-fluorescein antibody (Roche Diagnostics; $1: 500,1 \mathrm{~h}$ ) and the FITC-TSA Plus amplification kit (PerkinElmer), and the second detection was with peroxidase-conjugated anti-DIG antibody (Roche Diagnostics; 1:500, $1 \mathrm{~h}$ ) and the $\mathrm{Cy}_{3}$-TSA Plus amplification kit (PerkinElmer). Residual activities of peroxidase introduced during the first detection were inactivated by incubation of sections with $0.6 \% \mathrm{H}_{2} \mathrm{O}_{2}$ for $30 \mathrm{~min}$. The specificity of FISH was confirmed by blank labeling using control sense cRNA probes. Images were taken with an FV1000 confocal laser-scanning microscope (Olympus).

Electrophysiological recording. Under deep anesthesia with diethyl ether, rats were decapitated, and coronal brain slices through the DRN $\left(250 \mu \mathrm{m}\right.$ thick) were cut with a Leica VT1000S slicer in ice-cold low-Na ${ }^{+}$ solution with a specific composition (in $\mathrm{mM}$ ): 215 sucrose, $2.5 \mathrm{KCl}, 4$ $\mathrm{MgCl}_{2}, 4 \mathrm{MgSO}_{4}, 1 \mathrm{CaCl}_{2}, 26 \mathrm{NaHCO}_{3}, 1.6 \mathrm{NaH}_{2} \mathrm{PO}_{4}$, and 20 glucose bubbling with $95 \% \mathrm{O}_{2}$ and $5 \% \mathrm{CO}_{2}$. For recovery, slices were incubated for $30 \mathrm{~min}$ in a mixed solution of $50 \%$ low- $\mathrm{Na}^{+}$solution and $50 \%$ normal bathing solution [containing the following (in mM): $125 \mathrm{NaCl}$, $2.5 \mathrm{KCl}, 2 \mathrm{CaCl}_{2}, 1 \mathrm{MgSO}_{4}, 1.25 \mathrm{NaH}_{2} \mathrm{PO}_{4}, 26 \mathrm{NaHCO}_{3}$, and 20 glucose, $\mathrm{pH}$ 7.4], which was bubbled continuously with a mixture of $95 \% \mathrm{O}_{2}$ and $5 \% \mathrm{CO}_{2}$ at $37^{\circ} \mathrm{C}$, followed by a mixed solution of $10 \%$ low- $\mathrm{Na}^{+}$solution and $90 \%$ normal bathing solution at $37^{\circ} \mathrm{C}$. Whole-cell patch-clamp recordings were made from DRN neurons in coronal acute slices using an upright microscope (BX51WI; Olympus) equipped with an infraredCCD camera system (Hamamatsu Photonics) in normal bathing solution at $32^{\circ} \mathrm{C}$. The resistance of the patch pipette was $3-6 \mathrm{M} \Omega$ when filled with the standard intracellular solution containing the following (in mм): $6 \mathrm{KCl}, 130 \mathrm{~K}$-gluconate, $10 \mathrm{NaCl}, 10 \mathrm{HEPES}, 0.5 \mathrm{EGTA}, 0.1 \mathrm{CaCl}_{2}$, $2 \mathrm{MgCl}_{2}, 4 \mathrm{Na}$-ATP, and $0.4 \mathrm{Na}-\mathrm{GTP}, \mathrm{pH} 7.3$, adjusted with $\mathrm{KOH}$. The lateral wing subdivision of the DRN (DRL) was selected as the recording region because the density of GAD67-positive 5-HT neurons was relatively higher than in ventral or dorsal parts of the DRN (Hioki et al., 2010). After whole-cell recording from DR neurons held at a membrane potential of $-70 \mathrm{mV}$ and switched to current-clamp recording mode, membrane potentials were recorded with an Axopatch 200B amplifier (Molecular Devices) and obtained by stepwise current injections (from -0.2 to $0.5 \mathrm{nA}$; duration, $500 \mathrm{~ms}$ ). Capacitance compensation and bridge-balance adjustment were made simultaneously. The pCLAMP 9 software (Molecular Devices) was used for stimulation and data acquisition. Signals were filtered at $3 \mathrm{kHz}$ and digitized at $20 \mathrm{kHz}$. The liquid junction potential was $\sim 10 \mathrm{mV}$ between the pipette solution and the normal bath solution, which was subtracted from the recorded data. 

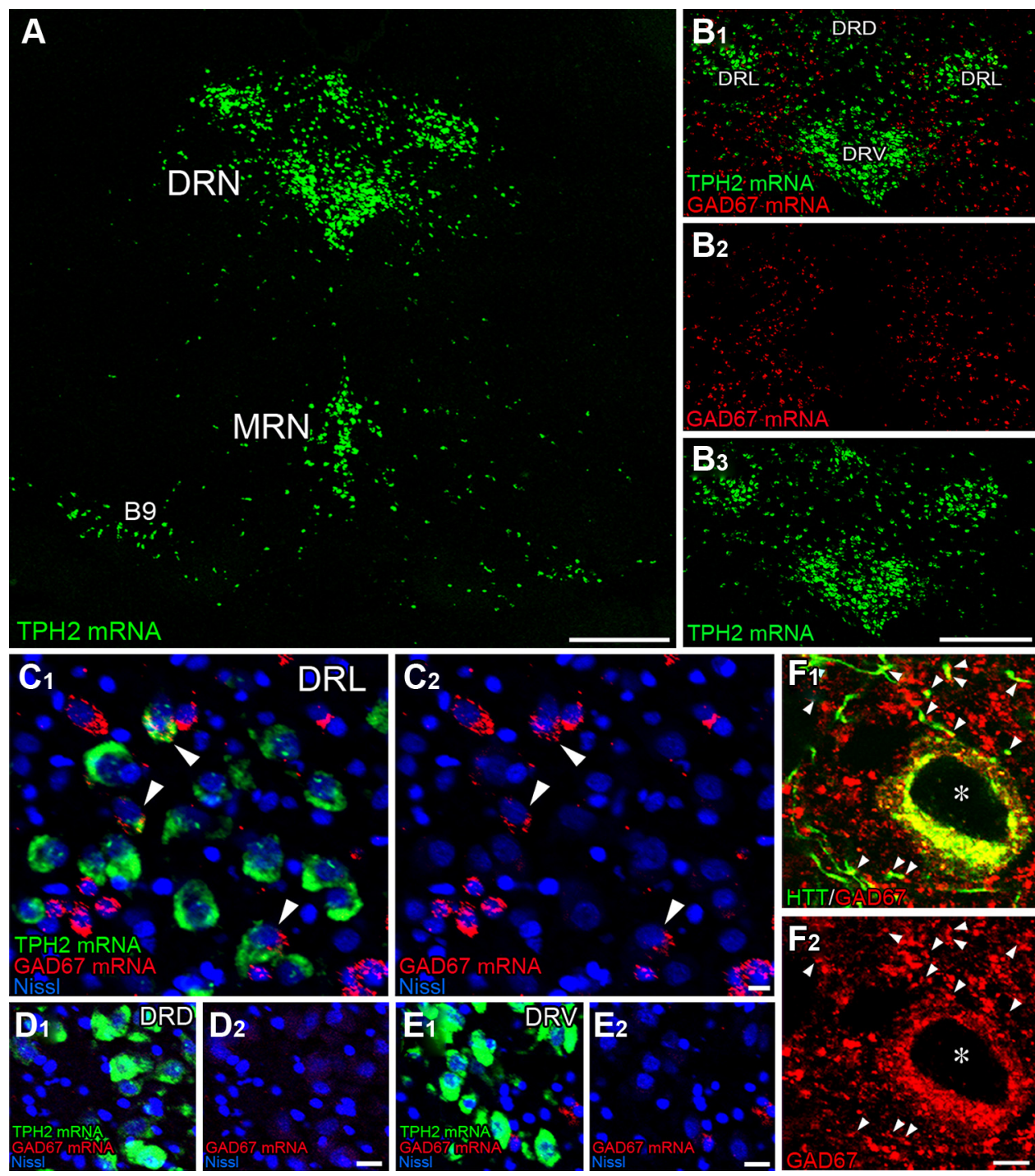

Figure 1. Selective localization of 5-HT/GAD67 neurons in the lateral wing of the dorsal raphe nucleus. $A$, FISH for TPH2 mRNA showing the distribution of 5-HTergic neurons in the DRN, median raphe nucleus (MRN), and B9 raphe nucleus (B9). $\boldsymbol{B}_{1}-\boldsymbol{E}_{2}$, Double FISH for TPH2 mRNA (green) and GAD67 mRNA (red) in the DRN $\left(\boldsymbol{B}_{1}-\boldsymbol{B}_{3}\right)$ with high-power views of the DRL $\left(\boldsymbol{C}_{1}, \boldsymbol{C}_{2}\right)$, DRD $\left(\boldsymbol{D}_{1}, \boldsymbol{D}_{2}\right)$, and DRV $\left(\boldsymbol{E}_{1}, \boldsymbol{E}_{2}\right)$. In the DRN, neurons expressing GAD67 mRNA (arrowheads) are preferentially distributed in the DRL. $\boldsymbol{F}_{1}, \boldsymbol{F}_{2}$, Double immunofluorescence HTT (green) and GAD67 (red) in the DRL. GAD67 is detected in perikarya (asterisk) and axonal varicosities (arrowheads) of 5-HT/GAD67 neurons. Scale bars: $\boldsymbol{A}_{1}$ (in $\boldsymbol{B}_{3}$ ) $\boldsymbol{B}_{1}-\boldsymbol{B}_{3}, 1 \mathrm{~mm}$; (in $\boldsymbol{C}_{2}$ ) $\boldsymbol{C}_{1}, \boldsymbol{C}_{2}$, (in $\boldsymbol{D}_{2}$ ) $\boldsymbol{D}_{1}, \boldsymbol{D}_{2}$ ( in $\boldsymbol{E}_{2}$ ) $\boldsymbol{E}_{1}, \boldsymbol{E}_{2}, 1 \mu \mathrm{m}$; (in $\boldsymbol{F}_{2}$ ) $\boldsymbol{F}_{1}, \boldsymbol{F}_{2}, 5 \mu \mathrm{m}$.

Single-cell $m R N A$ collection and reverse-transcription polymerase chain reaction. After whole-cell patch-clamp recording, the intracellular contents of each neuron were aspirated with negative pressure into the glasselectrode pipette that was used for recording and ejected into $10 \mu \mathrm{l}$ RNase-free water (Promega). These samples (putatively containing mRNA) were immediately stored at $-80^{\circ} \mathrm{C}$. The mRNA was converted to cDNA with the QuantiTect Reverse Transcription Kit (Qiagen). For cDNA amplification, PCR was performed with the SYBR GreenER qPCR SuperMix for ABI PRISM (Invitrogen) in the ABI PRISM 7000 Sequence Detection System (Applied Biosystems). The primer sequences and estimated product lengths are listed in Table 1. PCR was conducted under the following conditions: $50^{\circ} \mathrm{C}$ for $2 \mathrm{~min}$ and $95^{\circ} \mathrm{C}$ for $10 \mathrm{~min}$, followed by 40 cycles of $94^{\circ} \mathrm{C}$ for $30 \mathrm{~s}$ and $54^{\circ} \mathrm{C}$ for $30 \mathrm{~s}$ using a programmable thermal controller (PTC-100TM; MJ Research). PCR products were visualized using ethidium bromide staining after electrophoresis in a 3\% agarose gel. Amplification of neuron-specific enolase cDNA confirmed that aspiration from the neuron was successful. PCR reactions without cDNA templates (containing only a pipette solution, bath solution, or noncellular debris) or with non-reverse transcription (RT) template were used as negative controls.
Open field stress. The open field (OF) stress test was used to induce mild and novel environmental stress on rats. The OF apparatus was a square chamber ( $90 \mathrm{~cm}$ long by $90 \mathrm{~cm}$ wide by $40 \mathrm{~cm}$ high). The central or peripheral zone was defined as a central square of $30 \mathrm{~cm}$ length by 30 $\mathrm{cm}$ width or a $10 \mathrm{~cm}$ width of inner circumference, respectively. To evaluate the locomotor activity, the traveled distance was recorded and automatically analyzed by the LimeLight 2 software package (Actimetrics), and the total number of crossings (the times animals crossed the lines dividing $9 \times 9$ squares in the open field) was also recorded for 30 min. Anxiolytic drug, diazepam, or vehicle ( $0.9 \%$ saline containing $1 \%$ arabic gum) was administrated intraperitoneally $30 \mathrm{~min}$ before exposing the OF apparatus. Tested rats and home cage controls were fixed for immunohistochemistry $2 \mathrm{~h}$ after OF stress.

Contextual fear conditioning stress. The contextual fear conditioning (CFC) stress test was used to induce severe and memory-dependent stress on rats. The detailed procedures were described previously (Ohmura et al., 2008, 2010). To quantify fear responses, electrical footshocks were administered five times $(2 \mathrm{~s} ; 0.3 \mathrm{~mA} ; 30 \mathrm{~s}$ intervals $)$ in a chamber $24 \mathrm{~h}$ before the test. Non-footshock rats, exposed only to the chamber, were used as control groups. Rats were reexposed to the cham- 
ber without footshocks for $15 \mathrm{~min}$, and freezing behavior was analyzed automatically by the FreezeFrame software package (Actimetrics). Freezing behavior was defined as a lack of movement, except for respiration, accompanied by an arched back and retraction of the ears. We intraperitoneally administrated diazepam or vehicle $30 \mathrm{~min}$ before reexposure to the shock box. Tested rats were fixed for immunohistochemistry $2 \mathrm{~h}$ after CFC stress.

Semiquantitative cell counting. Procedures of immunoperoxidase-stained c-Fos-positive cell counting were reported previously (Izumi et al., 2011). We selected representative sections positioned between 6.95 and $7.05 \mathrm{~mm}$ posterior to bregma from each rat. Unit areas of the brain were digitally recorded with a CCD camera (CCD-IRIS; Sony) connected to a photomicroscope (BX50; Olympus) and a densitometric video image analysis system (MCID system; InterFocus Imaging). The number of c-Fospositive cells was counted in three rostrocaudal sections every $20 \mu \mathrm{m}$ in the DRD, DRV, and DRL, and assessed by automated selection of cells within the unit areas $(200 \times 200 \mu \mathrm{m})$ that satisfied the following criteria: (1) the gray value of the cell nucleus was higher than the threshold value (threshold gray value $5-50 \%$ higher than the background gray value), and (2) nuclei had a diameter of $4-12 \mu \mathrm{m}$ (to exclude cell debris and artifacts). The background gray value was determined in a part of each unit area containing no nuclei. Finally, the number of c-Fos-positive cells was averaged in respective regions of the DRN.

Data analysis. Differences between multiple group comparisons were performed using a oneway or two-way ANOVA with Bonferroni's post hoc test, if the differences in the variance of these multiple groups were not significant. The $\alpha$ level was set at $5 \%$. When the difference in the variance of multiple groups was significant, a Kruskal-Wallis test was performed. Subsequently, multiple comparison was performed using the Mann-Whitney $U$ test, setting the $\alpha$ level at 5\%; that is, the $\alpha$ level was set at $1.7 \%(5 \% / 3)$, $0.71 \%(5 \% / 7)$, or $0.33 \%(5 \% / 15)$ for multiple comparisons, because the number of comparisons was 3 (three groups), 7 (four groups), or 15 (nine groups), respectively. Differences between two groups were compared using Student's $t$ test when the difference in the variance of two groups was not significant. If the difference of variance in two groups was significant, comparisons were performed using the Mann-Whitney $U$ test.

\section{Results \\ 5-HT/GAD67 neurons are distributed in the lateral wing of DRN}

To identify 5-HTergic and GABAergic neurons, we first examined the cellular expression of TPH2 and GAD67 mRNAs, respectively, by double-labeling FISH. TPH2 mRNA was strongly expressed in the DRN, median raphe nucleus, and $\mathrm{B} 9$ raphe nucleus (Fig. $1 A$ ). In the DRN, TPH2 mRNA was detected in the DRL, DRD, and DRV (Fig. $1 B_{1}$, green). GAD67 mRNAexpressing neurons were densely distributed in the DRL, whereas they were few in the DRD and DRV (Fig. $1 B_{1}$, red). In the DRL, some neurons were colabeled for TPH2 and GAD67 mRNAs (arrowheads; $17.5 \%$, 36 of 205 cells), while others were labeled for
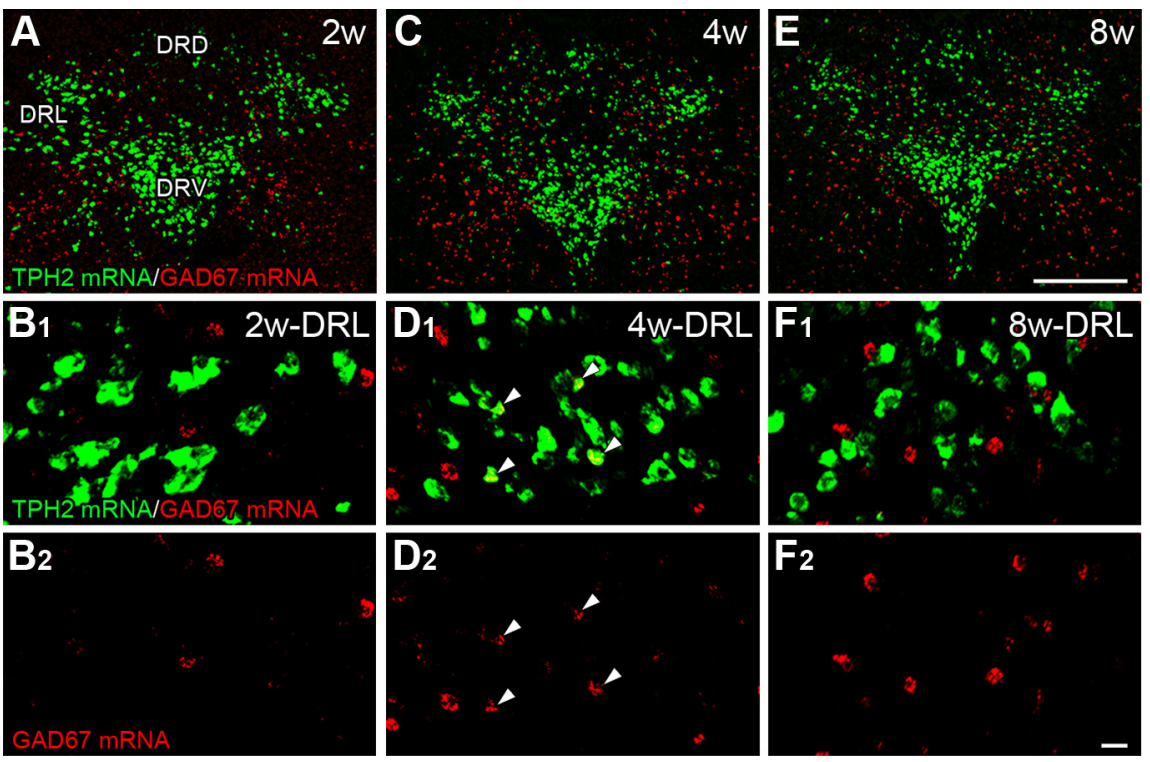

Figure 2. 5-HT/GAD67 neurons in the DRL transiently increase at $\sim 4$ weeks of age. $\boldsymbol{A}-\boldsymbol{F}$, Double FISH for TPH2 mRNA (green) and GAD67 mRNA (red) in the DRN $(\boldsymbol{A}, \boldsymbol{C}, \boldsymbol{E})$ with high-power images of the DRL $\left(\boldsymbol{B}_{1}, \boldsymbol{B}_{2}, \boldsymbol{D}_{1}, \boldsymbol{D}_{2}, \boldsymbol{F}_{1}, \boldsymbol{F}_{2}\right)$ at 2,4 , and 8 weeks of age. 5-HT neurons expressing GAD67 mRNA (arrowheads) are occasionally observed in the DRL at 4 weeks of age $\left(\boldsymbol{D}_{1}, \boldsymbol{D}_{2}\right)$, but not in 2

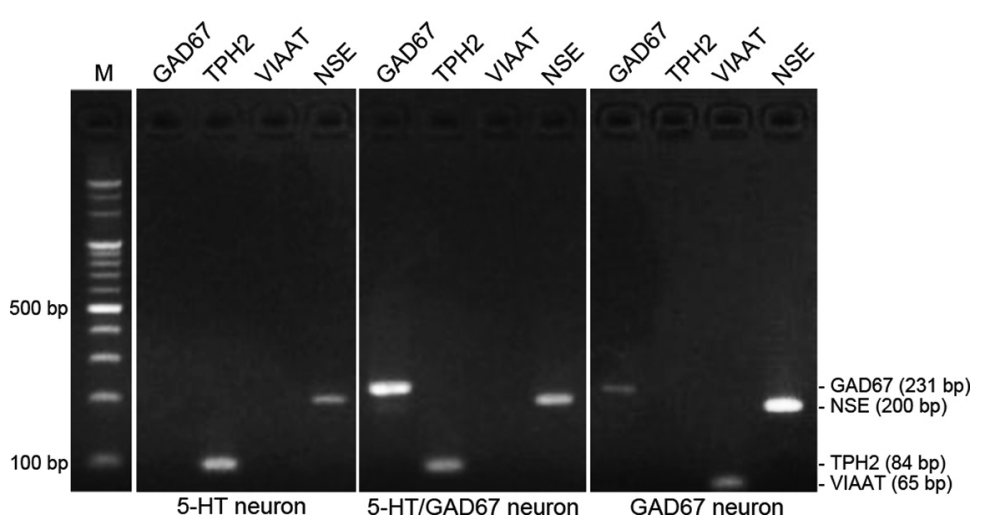

Figure 3. Patterns of single-cell RT-PCR in the DRL. Three neuron types are classified based on the expression of TPH2 and (left), 5-HT/GAD67 neuron expressing both TPH2 and GAD67 mRNAs (middle), and GAD67 neuron expressing GAD67 mRNA only (right). Note that 5-HT neurons and 5-HT/GAD67 neurons express no detectible levels of VIAAT mRNA, whereas GAD67 neurons highly express it. Neuron-specific enolase (NSE) is used as a positive control. Lane M indicates a 100 bp DNA ladder. Values in parentheses indicate the expected length of each PCR product.

TPH2 mRNA or GAD67 mRNA (Fig. $1 C_{1}, C_{2}$ ). Neurons coexpressing TPH2 mRNA and GAD67 mRNA were very rare in the DRD $\left(2.1 \%, 2\right.$ of 94 cells; Fig. $\left.1 D_{1}, D_{2}\right)$ and DRV (0\%, 0 of 219; Fig. $\left.1 E_{1}, E_{2}\right)$. By double immunofluorescence for HTT, a marker for 5-HTergic neurons, some 5-HT neurons in the DRL were demonstrated to coexpress GAD67 in their perikarya and axonal varicosities (Fig. $1 F_{1}, F_{2}$, asterisks and arrowheads, respectively). Thus, 5-HT/GAD67 neurons are mainly distributed in the DRL.

Furthermore, the extent of GAD67 expression in DRL 5-HT neurons differed significantly among different age groups. By double-labeling FISH, we found that the percentage of 5-HT/GAD67 neurons at 4 weeks of age was $22.0 \%$ of the total TPH2 mRNA-positive cells ( 27 of 123 cells; Fig. $2 C, D_{1}, D_{2}$ ). This was considerably higher than the percentages at 2 and 8 weeks [0.5\% ( 1 of 190 cells) and $1.7 \%$ (3 of 179 cells), respectively; Fig. $\left.2 A, B_{1}, B_{2}, E, F_{1}, F_{2}\right]$. Thus, GAD67 expression in 5-HT neurons transiently increases at $\sim 4$ weeks and decreases thereafter. 

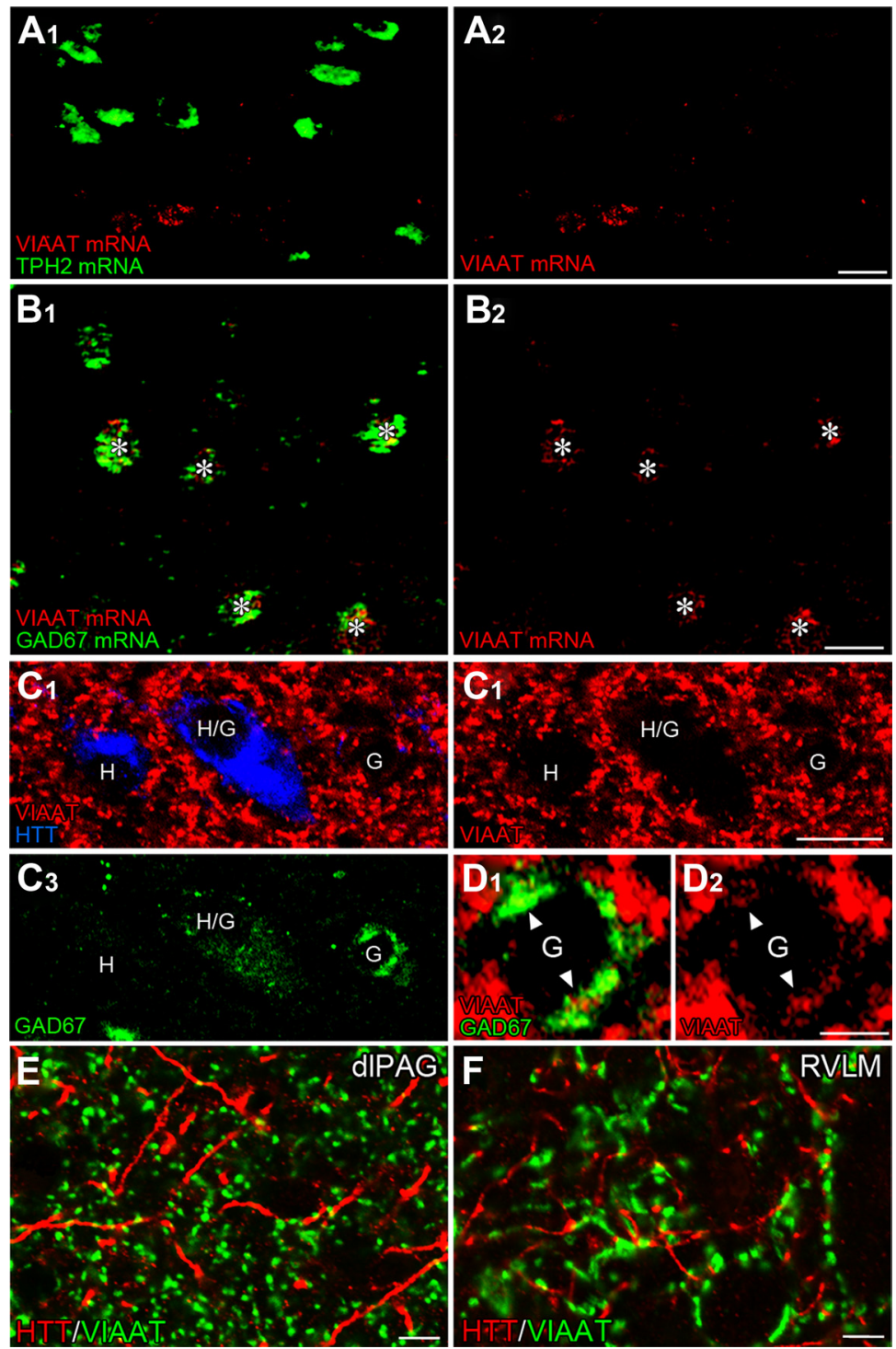

Figure 4. Lack of VIAAT expression in 5-HT and 5-HT/GAD67 neurons in the DRL. $\boldsymbol{A}_{1}-\boldsymbol{B}_{1}$, Double FISH for VIAAT mRNA (red $\boldsymbol{A}_{\boldsymbol{1}}-\boldsymbol{B}_{1}$ ) and TPH2 mRNA (green; $\boldsymbol{A}_{1}, \boldsymbol{A}_{2}$ ) or GAD67 mRNA (green; $\boldsymbol{B}_{1}$ ). Signals for VIAAT mRNA are detected in most of the GAD67 mRNA-positive cells (asterisks; $\left.\boldsymbol{B}_{1}\right)$, but not in TPH2 mRNA-positive neurons $\left(\boldsymbol{A}_{1}, \boldsymbol{A}_{2}\right) . \boldsymbol{C}_{\mathbf{1}}-\boldsymbol{D}_{2}$, Triple immunofluorescence for HTT (blue), GAD67 (green), and VIAAT (red). There are three neuron types based on the expression of HTT and GAD67: HTT-positive 5-HT neurons (H), HTT/GAD67-positive 5-HT/GAD67 neurons (H/G), and GAD67-positive GAD67 neurons (G). The images in $\boldsymbol{D}_{\mathbf{1}}$ and $\boldsymbol{D}_{\mathbf{2}}$ are enlarged views of a GAD67 neuron in $\boldsymbol{C}_{\mathbf{1}}-\boldsymbol{C}_{\mathbf{3}}$. Note the diffuse VIAAT immunolabeling in perikarya of GAD67 neurons, but not 5-HT or 5-HT/GAD67 neurons. $\boldsymbol{E}, \boldsymbol{F}$, Double immunofluorescence for HTT (red) and VIAAT (green) in the dIPAG (E) and the RVLM $(\boldsymbol{F})$. Scale bars: $A_{2}$ (for $A_{1}, A_{2}$ ), $C_{2}$ (for $C_{1}-C_{3}$ ), $20 \mu \mathrm{m} ; B_{1}, D_{2}$ (for $\left.D_{1}, D_{2}\right), E, F, 5 \mu \mathrm{m}$.

To quantitatively classify the neurochemical phenotype of DRL neurons, we performed single-cell RT-PCR using the total RNA sampled from individual neurons after the whole-cell patch-clamp recording (see Fig. 6). Representative patterns are shown in Figure 3. According to the pattern of mRNA expression, DRL neurons were classified into four types: 5-HT neurons expressing TPH2 mRNA only (Fig. 3, left), 5-HT/GAD67 neurons expressing both TPH2 and GAD67 mRNAs (middle), GAD67 neurons expressing GAD67 mRNA only (right), and undefined neurons lacking neither $\mathrm{mR}$ NAs. Of the total analyzed 82 neurons, 5-HT neurons accounted for $52.4 \%$ (43 neurons), 5-HT/GAD67 neuron for $12.2 \%$ (10 neurons), GAD67 neuron for 4.9\% (4 neurons), and undefined neurons for 30.5\% (25 neurons). Therefore, 5-HT/GAD67 neurons are selectively distributed in the lateral wing of DRN and constitute $12 \%$ of the total DRL neurons.

\section{5-HT/GAD67 neurons lack VIAAT}

We also examined the expression of VIAAT mRNA by single-cell RT-PCR (Fig. 4). All of the GAD67 neurons examined coexpressed VIAAT mRNA. Unexpectedly, none of the 5-HT/GAD67 neurons showed amplified signals for VIAAT mRNA. The lack of VIAAT expression in 5-HT/GAD67 neurons was further assessed by FISH and immunofluorescence (Fig. 5). Because the absence of VIAAT mRNA in 5-HT/GAD67 neurons was unexpected, we tested this by FISH as well. Although most of the GAD67 mRNA-expressing neurons coexpressed VIAAT mRNA in the DRL (Fig. $5 B_{1}, B_{2}$, asterisks; 327 of 355 cells, $92.1 \%$ ), VIAAT mRNA was detected in none of the TPH2 mRNA-expressing neurons (Fig. 5A; 0 of 36 cells). Triple immunofluorescence for GAD67, VIAAT, and HTT showed that GAD67-positive neurons (Fig. $5 C_{1}-$ $\left.\mathrm{D}_{2}, \mathrm{G}\right)$ were diffusely labeled for VIAAT. However, perikarya of 5-HT neurons (Fig. $5 C_{1}, C_{2}, \mathrm{H}$ ) and 5-HT/GAD67 neurons (Fig. $5 C_{1}, C_{2}, \mathrm{H} / \mathrm{G}$ ) lacked immunolabeling for VIAAT. The lack of VIAAT labeling was also true in HTT-positive axons and terminals in the dorsolateral periaqueductal gray (dlPAG) and the rostral ventrolateral medulla (RVLM), i.e., major projection targets of the DRL (Fig. $5 E_{1}, E_{2}$ ). Thus, 5-HT/GAD67 neurons lack the expression of VIAAT, a molecule essential for vesicular filling of GABA.

\section{5-HT/GAD67 neurons express GAT-1}

Deletion of VIAAT gene in mice severely reduces, but does not completely eliminate, inhibitory neurotransmission (Wojcik et al., 2006). This fact is taken to be due to the efflux of GABA by reverse operation of plasmalemmal GATs (Attwell et al., 1993). By FISH and immunofluorescence, we investigated in the DRL the expression of GAT-1 (Fig. 5), a GAT subtype preferentially localized on GABAergic neurons (Itouji et al., 1996; Morara et al., 1996). Double FISH labeling (Fig. $5 A$ ) revealed that there were a few neurons coexpressing GAT- 1 and TPH 2 mRNAs in the DRL (Fig. $5 B_{1}, B_{2}$, asterisks), but not in the DRD (Fig. $5 C_{1}, C_{2}$ ), or DRV (Fig. $5 D_{1}, D_{2}$ ). By immunofluorescence, GAT-1 labeling was frequently found along neuronal processes labeled for HTT (Fig. $5 E_{1}, E_{2}$, white arrowheads) and also along processes protruding from perikarya of 5-HT/GAD67 neurons colabeled for HTT and GAD67 (yellow arrowheads). Therefore, 5-HT/GAD67 neurons express GAT-1, a molecule mediating GABA transport across the cell membrane.

\section{Distinct electrophysiological properties of 5-HT/GAD67 neurons}

To examine functional characteristics of 5-HT/GAD67 neurons, whole-cell patch-clamp recordings were performed from DRL neurons in acute coronal slices (Fig. 6A,B). After each recording, 

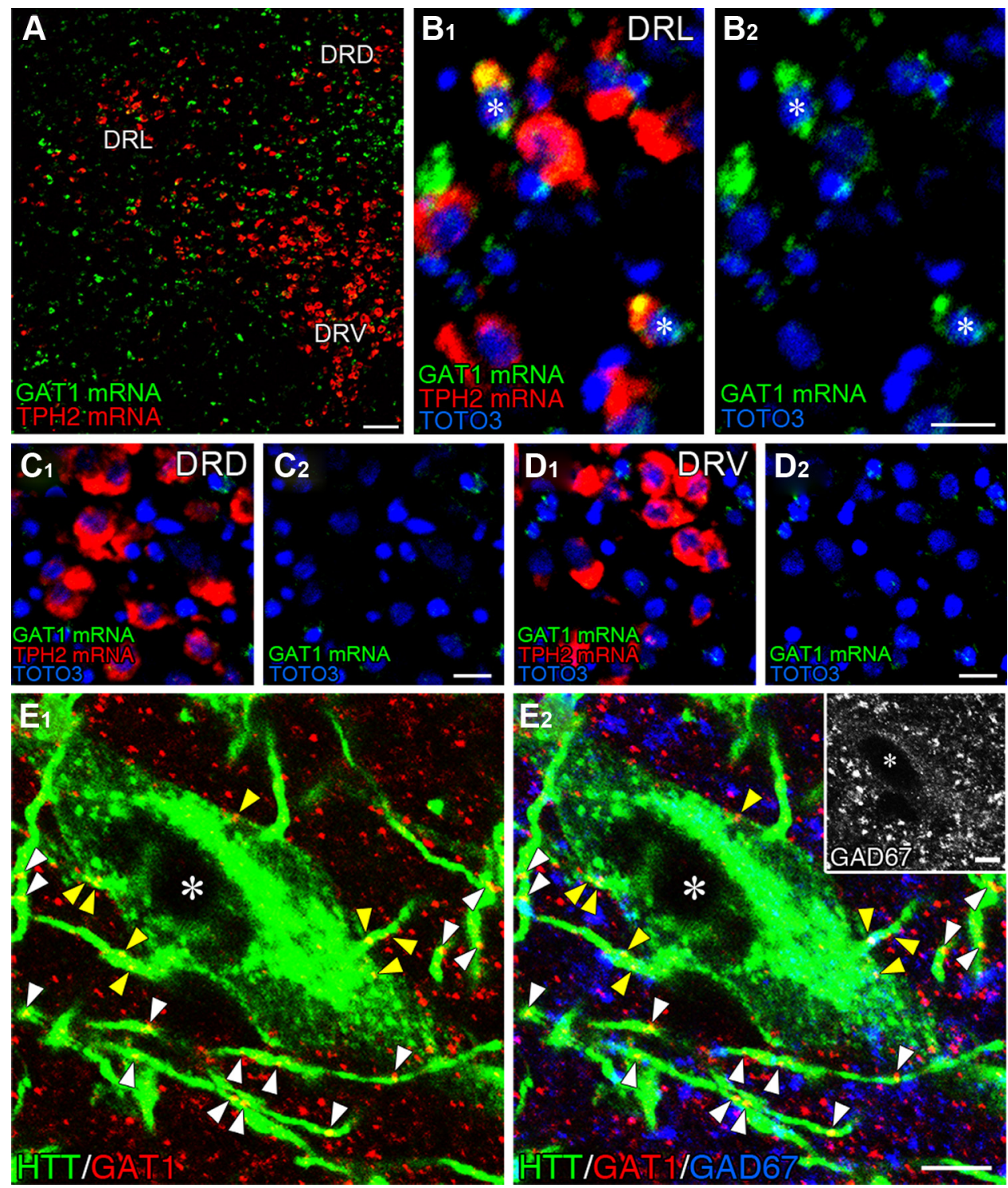

Figure 5. Expression of GAT-1 in 5-HT/GAD67 neurons. $\boldsymbol{A}-\boldsymbol{D}_{2}$, Double FISH for GAT-1 (green) and TPH2 (red) mRNA in the DRN $(\boldsymbol{A})$ with high-power views of the DRL $\left(\boldsymbol{B}_{1}, \boldsymbol{B}_{2}\right)$, DRD $\left(\boldsymbol{C}_{1}, \boldsymbol{C}_{2}\right)$, and $\operatorname{DRV}\left(\boldsymbol{D}_{1}, \boldsymbol{D}_{2}\right)$. Some neurons in the DRL coexpress GAT1 and TPH2 mRNAs (asterisks). $\boldsymbol{E}_{1}, \boldsymbol{E}_{2}$, Triple immunofluorescence for HTT (green), GAT-1 (red), and GAD67 (blue) in the DRL. GAT-1 is often detected in HTT-positive fibers (white arrowheads), and also in somatodendritic processes protruding from the soma of HTT/GAD67-positive neurons (yellow arrowheads). The inset shows diffuse perikaryal labeling for GAD67 in this 5-HT/GAD67 neuron (asterisk). Scale bars: $\boldsymbol{A}_{,} \boldsymbol{B}_{2}\left(\right.$ for $\left.\boldsymbol{B}_{1}, \boldsymbol{B}_{2}\right), \boldsymbol{C}_{2}\left(\right.$ for $\left.\boldsymbol{C}_{1}, \boldsymbol{C}_{2}\right), \boldsymbol{D}_{2}$ (for $\left.\boldsymbol{D}_{1}, \boldsymbol{D}_{2}\right), 20 \mu \mathrm{m} ; \boldsymbol{E}_{2}$ (for $\boldsymbol{E}_{1}, \boldsymbol{E}_{2}$ ), inset, $5 \mu \mathrm{m}$.

5-HT neurons, 5-HT/GAD67 neurons, and GAD67 neurons were classified by single-cell RT-PCR (Fig. 3). In current-clamp recordings, the amplitude of action potentials in GAD67 neurons was significantly smaller than that in other neuron types $\left(F_{(2,54)}=4.372 ; p<0.05\right)$, while no differences were found in the duration of action potentials, afterhyperpolarization, or resting membrane potential (Table 2). Figure $6 \mathrm{C}$ shows a representative recording of membrane potential changes evoked by a negative current injection to 5-HT neurons, 5-HT/GAD67 neurons, and GAD67 neurons, from which the current-voltage characteristics were plotted (Fig. 6D). The input resistance in 5-HT/GAD67 neurons $(191.02 \pm 25.85 \mathrm{M} \Omega$ ) was significantly lower than that in 5-HT neurons $(360.82 \pm 20.72 \mathrm{M} \Omega)$ and GAD67 neurons $\left(418.41 \pm 95.49 \mathrm{M} \Omega ; F_{(2,54)}=8.51 ; p<0.05\right)$. Figure $6, E$ and $F$, shows the firing pattern during injection of $0.3 \mathrm{nA}$ positive currents. The firing frequency in 5-HT/GAD67 neurons was significantly lower than that in 5-HT neurons and GAD67 neurons (5-HT neurons, $37.42 \pm 3.26 \mathrm{~Hz}$; 5-HT/GAD67 neurons,
$12.90 \pm 1.77 \mathrm{~Hz}$; GAD67 neurons, $87.50 \pm 19.62 \mathrm{~Hz} ; F_{(2,54)}=$ 20.91; $p<0.05$; Fig. $6 G$ ). Therefore, 5-HT/GAD67 neurons exhibit lower input resistance and firing frequency compared to other neuron types in the DRL. Moreover, 5-HT/GAD67 neurons show larger amplitudes of action potentials than GAD67 neurons.

Open field stress preferentially induces diazepam-sensitive c-Fos expression in the DRL

To compare the responsiveness of DRN neurons to innocuous stress, we placed animals to a novel OF arena and examined c-Fos expression $2 \mathrm{~h}$ after the OF stress test. In each subdivision of the DRN, the density of c-Fos-positive cells was significantly increased after OF stress (Fig. 7). Of these, OF stress induced significantly higher increase in the DRL $(447.66 \pm 104.92$ cells/ $\mathrm{mm}^{2} ; n=12$; Fig. $\left.7 D\right)$ than in the DRD (178.19 \pm 76.67 cells/ $\mathrm{mm}^{2} ; n=12$; Fig. $\left.7 E\right)$ and DRV $\left(182.66 \pm 76.50\right.$ cells $/ \mathrm{mm}^{2} ; n=$ $12 ; F_{(8,294)}=9.88 ; p<0.0033$; Fig. $\left.7 F\right)$. 


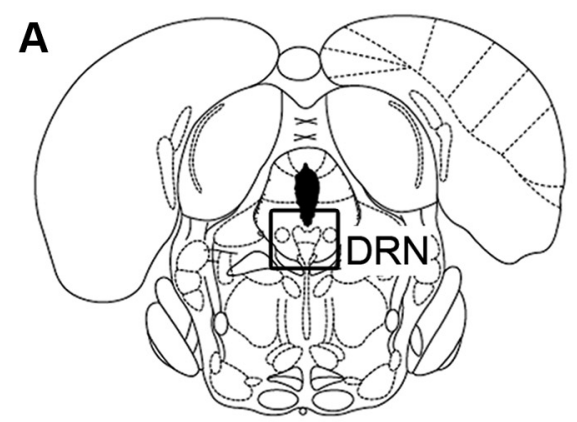

C
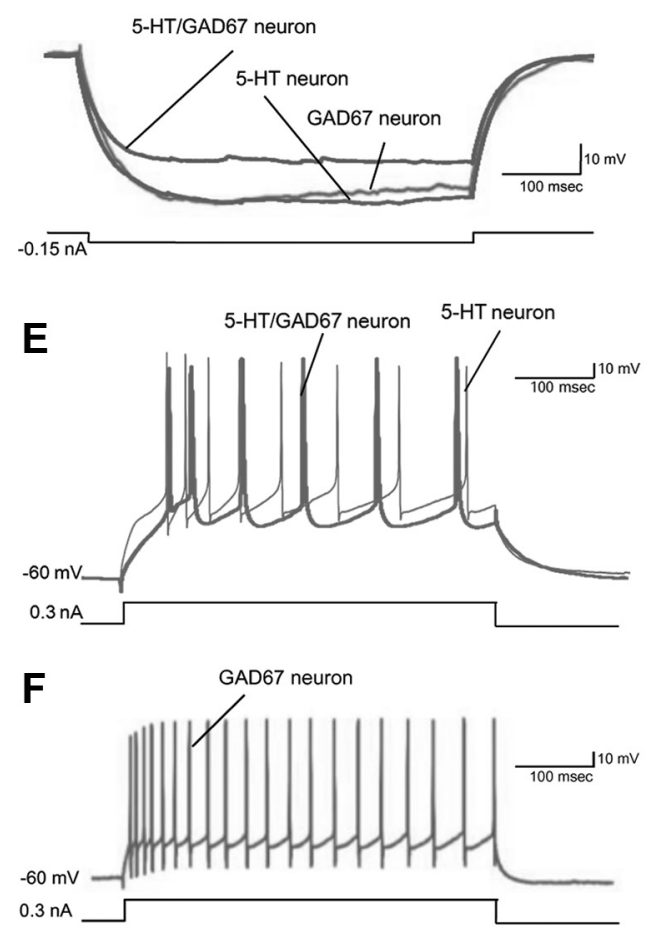

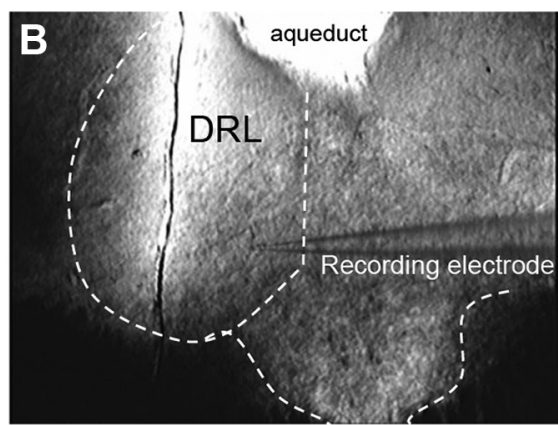

D
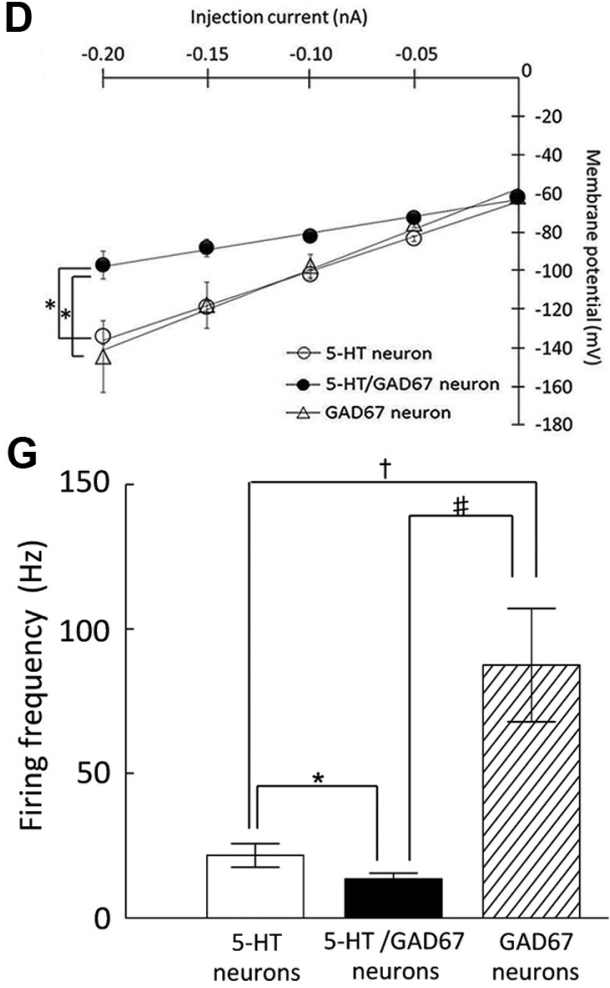

Figure 6. Electrophysiological characterization of DRN neurons using whole-cell patch-clamp recording. $A, B$, DRN position $(\boldsymbol{A})$ and representative photograph of a coronal slice submerged in our recording chamber depicting the position of an electrode for the recording of membrane potentials $(\boldsymbol{B})$. $\boldsymbol{C}$, Representative recording of membrane potential changes evoked by negative current injection to 5-HT neuron, 5-HT/GAD67 neuron, and GAD67 neuron. D, Summarized linear voltage-current plot for recorded cells from both neuronal types. The input resistance of 5-HT/GAD67 neurons $\left(191.02 \pm 25.82 \mathrm{M} \Omega\right.$ ) is significantly lower than 5 -HT neurons $\left(360.82 \pm 20.72 \mathrm{M} \Omega\right.$ ) and GAD67 neurons ( $\left.418.41 \pm 95.49 \mathrm{M} \Omega ; F_{(2,54)}=8.51 ;{ }^{*} p<0.05\right)$. E, $\boldsymbol{F}$, Representative recordings of membrane potential changes evoked by a positive current injection of $0.3 \mathrm{nA}$ to a 5 -HT neuron, 5 -HT/GAD67 neuron, and GAD67 neuron. G, Summarized bar graph of the firing frequency of 5-HT/GAD67 neurons, which is significantly lower than that of 5-HT neurons and GAD67 neurons (5-HT neurons, $37.42 \pm 3.26 \mathrm{~Hz} ; 5-\mathrm{HT} / \mathrm{GAD} 67$ neurons, $12.90 \pm 1.77 \mathrm{~Hz}$; GAD67 neurons, $87.50 \pm$ $\left.19.62 \mathrm{~Hz} ; F_{(2,54)}=20.905 ; *, \#,+00.05\right)$.

Table 2. Analysis of membrane potential parameters

\begin{tabular}{|c|c|c|c|}
\hline Parameter & $\begin{array}{l}\text { 5-HT neuron } \\
(n=43)\end{array}$ & $\begin{array}{l}5 \text {-HT/GAD67 neuron } \\
(n=10)\end{array}$ & $\begin{array}{l}\text { GAD67 neuron } \\
(n=4)\end{array}$ \\
\hline Resting membrane potential (mV) & $-61.82 \pm 1.67$ & $-64.91 \pm 4.14$ & $-52.13 \pm 17.17$ \\
\hline Threshold (mV) & $-27.36 \pm 1.05$ & $-31.06 \pm 1.50$ & $-24.06 \pm 7.04$ \\
\hline Action potential amplitude (mV) & $70.37 \pm 2.65$ & $68.94 \pm 3.94$ & $45.30 \pm 5.59^{*}$ \\
\hline Action potential duration (ms) & $2.22 \pm 0.12$ & $1.98 \pm 0.24$ & $1.78 \pm 0.22$ \\
\hline Afterhyperpolarization (mV) & $-25.66 \pm 1.22$ & $-24.14 \pm 1.31$ & $-29.00 \pm 7.91$ \\
\hline
\end{tabular}

Significantly lower amplitudes of action potentials are observed in GAD67 neurons among the three neuronal groups $\left(F_{(2,54)}=4.372 ;{ }^{*} p<0.05\right)$. No significant differences were found in the action potential duration $\left[F_{(2,54)}=0.982\right.$, not significant (n.s.) $]$, afterhyperpolarization $\left(F_{(2,54)}=0.856\right.$, n.s. $)$, or resting membrane potential $\left(F_{(2,54)}=1.707\right.$, n.s.) among the three groups.

We then tested whether the c-Fos expression was selectively induced due to emotional stress, especially anxiety, we administered diazepam, a major benzodiazepine anxiolytic drug, $30 \mathrm{~min}$ before OF stress test (Fig. 8). Low-dose diazepam (0.1 mg/kg, i.p.) did not affect OF stress-induced c-Fos expression in all three subdivisions (DRL, $332.42 \pm 173.33$ cells $/ \mathrm{mm}^{2}, n=6$; DRD, $175.13 \pm 54.86$ cells $/ \mathrm{mm}^{2}, n=6$; DRV, $178.33 \pm 56.80$ cells/ $\left.\mathrm{mm}^{2}, n=6\right)$. However, high-dose diazepam $(0.5 \mathrm{mg} / \mathrm{kg}$, i.p. $)$ significantly reduced c-Fos expression in the DRL (98.06 \pm 47.78 cells $/ \mathrm{mm}^{2} ; n=12$; Fig. $\left.8 A\right)$, but not in the DRD (185.47 \pm 51.46 cells $/ \mathrm{mm}^{2} ; n=12$; Fig. $\left.8 B\right)$ or DRV $\left(175.91 \pm 57.27\right.$ cells $/ \mathrm{mm}^{2}$, $n=12$; Fig. $8 C)\left(\mathrm{DRL}, F_{(5,174)}=23.85\right.$; DRD, $F_{(5,174)}=7.15$; DRV, $F_{(5,174)}=10.52 ; p<0.0071$ for each). Administration of high-dose diazepam increased the ratio of moving distance in the central zone of an OF arena (vehicle, $1.88 \pm 1.06 \%, n=12$; diazepam, $0.1 \mathrm{mg} / \mathrm{kg}, 1.97 \pm 1.15 \%, n=6 ; 0.5 \mathrm{mg} / \mathrm{kg}, 6.21 \pm$ $1.94 \%, n=12 ; F_{(2,27)}=26.94 ; p<0.05$; Fig. $\left.8 D\right)$ and reduced the ratio in the peripheral zone (vehicle, $81.39 \pm 5.02 \%, n=12$; diazepam, $0.1 \mathrm{mg} / \mathrm{kg}, 78.01 \pm 8.67 \%, n=6 ; 0.5 \mathrm{mg} / \mathrm{kg}, 71.20 \pm$ $5.75 \%, n=12 ; F_{(2,27)}=7.45 ; p<0.05$; Fig. $\left.8 E\right)$ without affecting 

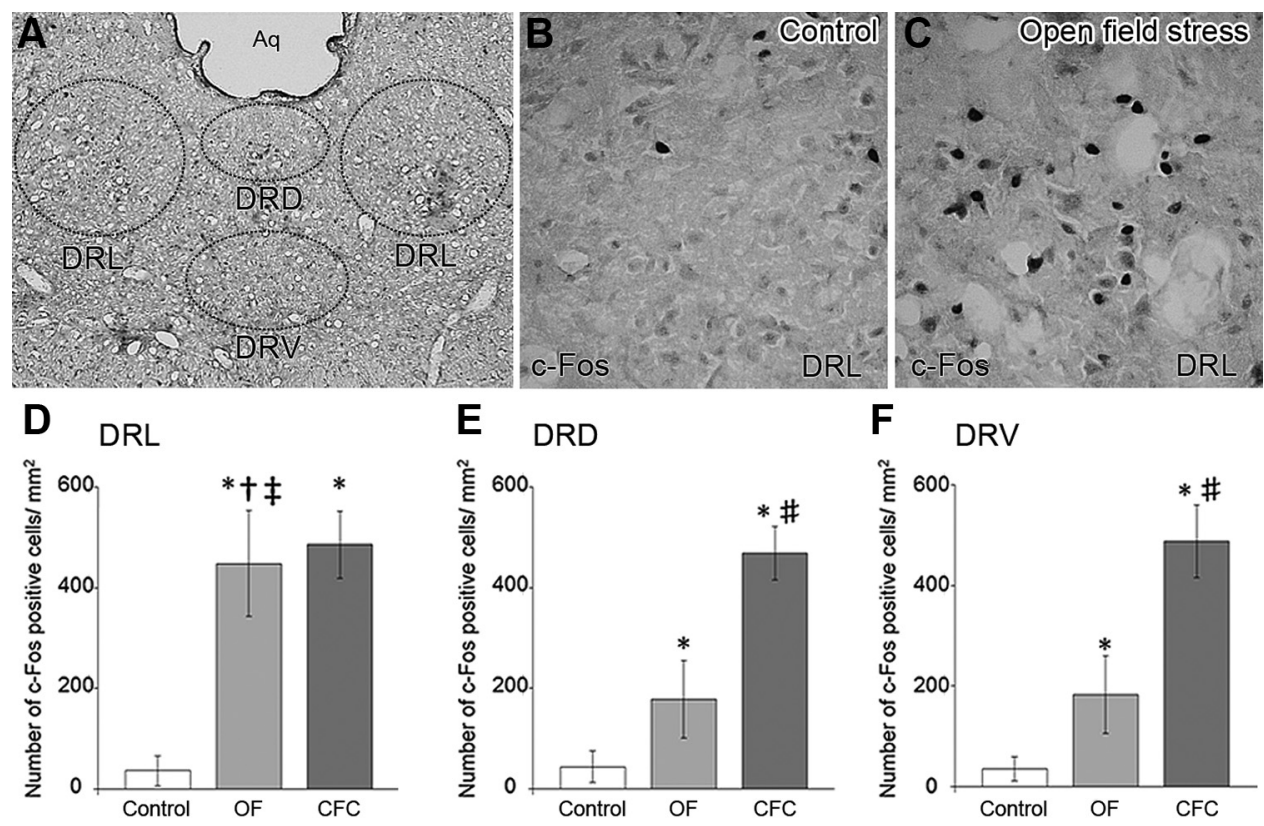

Figure 7. The number of c-Fos positive cells induced by emotional stress. A, A low-power photograph of c-Fos immunolabeling in the DRN. B, C, High-power photographs showing basal c-Fos expression of home cage controls $(\boldsymbol{B})$ and open field stress-induced c-Fos expression $(\boldsymbol{C})$ in the DRL. $\boldsymbol{D}-\boldsymbol{F}$, The number of stress-induced c-Fos-positive neurons in the DRL (D), DRD (E), and DRV $(\boldsymbol{F})$. The density of OF stress-induced c-Fos-positive neurons is significantly higher in the DRL $\left(447.66 \pm 104.92 \mathrm{cells} / \mathrm{mm}^{2} ; n=12\right)$ than in the DRD $\left(178.19 \pm 76.67 \mathrm{cells} / \mathrm{mm}^{2} ; n=12\right)$ and DRV $\left(182.66 \pm 76.50\right.$ cells $\left./ \mathrm{mm}^{2} ; n=12\right)$. CFC stress-induced c-Fos expression is not different among the DRL ( $\left.485.02 \pm 65.00 \mathrm{cells} / \mathrm{mm}^{2} ; n=10\right), \mathrm{DRD}\left(467.50 \pm 52.72 \mathrm{cells} / \mathrm{mm} \mathrm{m}^{2} ; n=10\right)$, and DRV (487.76 \pm 72.27 cells $/ \mathrm{mm}^{2} ; n=10 ; F_{(8.294)}=9.88 ; p<0.0033$ ). ${ }^{*} p<0.0033$ (control vs OF or CFC in the same brain region); ${ }^{\#} p<0.0033$ (OF vs CFC in the same brain region); ${ }^{\dagger} p<0.0033$ ( $0 \mathrm{~F}$ in the DRD vs OF in the DRL); ${ }^{\ddagger} p<0.0033$ (OF in the DRV vs OF in the DRL). Aq, Aqueduct.

the total moving distance (vehicle, $3746.22 \pm 1168.60 \mathrm{~cm}, n=12$; diazepam, $0.1 \mathrm{mg} / \mathrm{kg}, 3174.31 \pm 731.40 \mathrm{~cm}, n=6 ; 0.5 \mathrm{mg} / \mathrm{kg}$, $3778.29 \pm 1316.09 \mathrm{~cm}, n=12 ; F_{(2,27)}=0.56$, not significant; Fig. $8 F)$. Thus, the high-dose diazepam lowers the anxiety level. Therefore, the DRL is more responsive to innocuous OF stress than the DRD and DRV, and an effective dose of diazepam does suppress OF stress-induced c-Fos expression in the DRL.

\section{Contextual fear conditioning stress induces diazepam- sensitive c-Fos expression in all DRN subdivisions}

When exposing animals to CFC stress, a memory-dependent, noxious emotional stress, robust increase in the density of c-Fospositive cells was observed in all three subdivisions of the DRN (DRL, $485.02 \pm 65.00$ cells $/ \mathrm{mm}^{2}, n=10$; DRD, $467.50 \pm 52.72$ cells $/ \mathrm{mm}^{2}, n=10 ; \mathrm{DRV}, 487.76 \pm 77.27$ cells $/ \mathrm{mm}^{2}$ ); however, no significant regional differences were discerned in the CFC stress test (Fig. $\left.7 D-F ; F_{(8,294)}=9.88 ; p<0.0033\right)$. Likewise, highdose diazepam significantly suppressed CFC stress-induced c-Fos expression in all three subdivisions of the DRN (DRL, $233.63 \pm 78.60$ cells $/ \mathrm{mm}^{2}, n=10, F_{(3,92)}=5.52$, Fig. 9A; DRD, $169.04 \pm 52.05$ cells $/ \mathrm{mm}^{2}, n=10, F_{(3,92)}=0.22$, Fig. 9B; DRV, $171.98 \pm 82.39$ cells $/ \mathrm{mm}^{2}, n=10, F_{(3,92)}=6.28$, Fig. $9 C ; p<$ 0.017 for each). CFC stress-induced freezing behaviors were also reduced significantly with high-dose diazepam (control plus vehicle, $21.16 \pm 4.41 \%$; control plus diazepam, $0.5 \mathrm{mg} / \mathrm{kg}, 18.04 \pm$ $1.90 \% ; n=6$, respectively; CFC plus vehicle, $69.93 \pm 10.43 \%$; CFC plus diazepam, $0.5 \mathrm{mg} / \mathrm{kg}, 35.51 \pm 13.31 \%$; $n=10$, respectively; Fig. $\left.9 D ; F_{(3,28)}=2.83 ; p<0.05\right)$. Thus, noxious emotional stress induces diazepam-sensitive c-Fos expression in all DRN subdivisions nonselectively.

\section{5-HT/GAD67 neurons are more responsive to OF stress than to CFC stress}

Finally, we examined which types of DRL neurons were responsive to emotional stress by triple immunofluorescence for c-Fos,
TPH2, and PV. To identify GABAergic neurons, we adopted PV instead of GAD67, because most of the PV-positive neurons were labeled for GAD67 ( 15 of 18 cells; 83\%), and also because intense somatic labeling for PV was suited for reliable cell counting (Fig. $\left.10 A_{1}-A_{3}\right)$. We calculated the percentage of PV-positive neurons in the total neurons colabeled for TPH2 and c-Fos (Fig. $10 B_{1}-$ $\left.B_{4}\right)$. In OF stress test, the majority of TPH2/c-Fos-positive neurons (128 of 199 cells; 64.3\%) were PV positive (Fig. 10C, left). In the CFC stress test, the majority of TPH2/c-Fos-positive neurons (210 of 352 cells; 59.7\%) were PV negative (Fig. 10C, right). Therefore, 5-HT/GAD67 neurons in the DRL are more responsive to OF stress than CFC stress.

\section{Discussion}

The DRN, the primary center of 5-HTergic projections to the entire forebrain and limbic regions, is comprised of heterogeneous subnuclei that have distinct morphological features and afferent and efferent connections. Growing evidence suggests that anatomically distinct subregions serve distinct functions, and neurochemical heterogeneity in the nucleus generates further complexity. In this study, we examined 5-HT/GAD67 neurons in the rat DRN and have disclosed their distinct anatomical, neurochemical, and electrophysiological properties and also their distinct responsiveness to emotional stressors.

In the DRN, significant populations of 5-HT-producing neurons coexpress various neurotransmitters, including dopamine, GABA, glutamate, nitric oxide, and neuropeptides such as corticotropin-releasing factor (Hioki et al., 2010). In the present study, we showed that 5-HT/GAD67 neurons were selectively located in the DRL. Considering that VGLUT3, GAD67, and tyrosine hydroxylase are expressed in distinct subregions and neuronal populations within the DRN (Hioki et al., 2010), it is likely that 5-HT/GAD67 neurons comprise a distinct subset in the DRN. We also revealed that 5-HT/GAD67 neurons, which were identified as those coexpressing TPH2 and GAD67 mRNAs, con- 

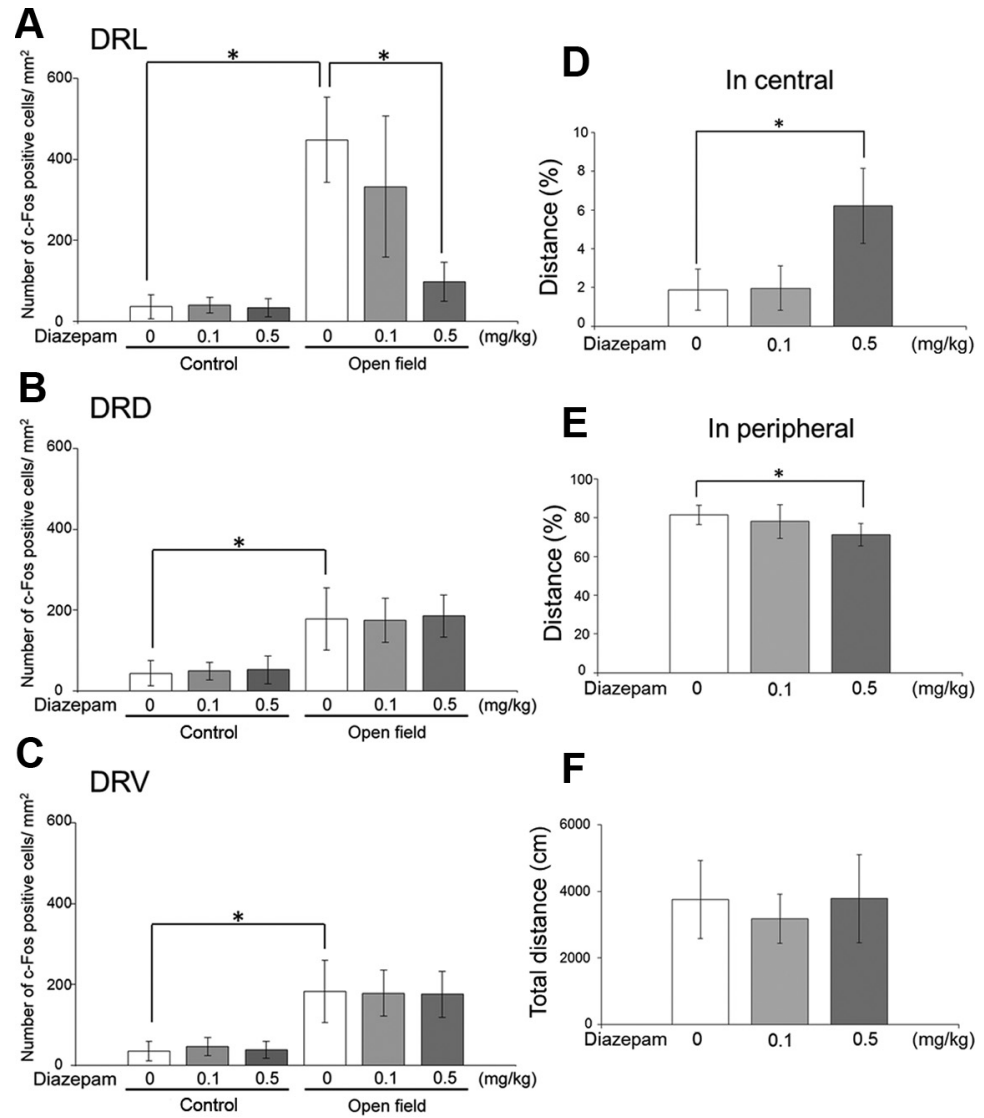

Figure 8. A high dose of diazepam suppresses OF stress-induced c-Fos expression in the DRL and exerts anxiolytic effect on open

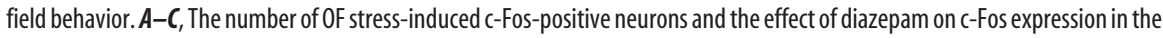
$\operatorname{DRL}(\boldsymbol{A}), \operatorname{DRD}(\boldsymbol{B})$, and DRV $(\boldsymbol{C})$. Control rats are kept in their home cages. OF stress-induced c-Fos expression is not affected by a low dose of diazepam $(0.1 \mathrm{mg} / \mathrm{kg}$, i.p.) in each subdivision of the DRN. However, this expression is reduced with $0.5 \mathrm{mg} / \mathrm{kg}$ diazepam in the DRL $\left(98.06 \pm 47.78\right.$ cells $\left./ \mathrm{mm}^{2} ; F_{(5,174)}=23.85 ; n=12\right)$, but not the DRD $\left(185.47 \pm 51.46 \mathrm{cells} / \mathrm{mm}^{2} ; F_{(5,174)}=7.15 ; n=\right.$ 12) or DRV (175.91 \pm 57.27 cells $\left./ \mathrm{mm}^{2} ; F_{(5,174)}=10.52 ; n=12\right) .{ }^{*} p<0.0071$ for each. $\boldsymbol{D}-\boldsymbol{F}$, The anxiolytic effect of diazepam on open field behavior. Diazepam $(0.5 \mathrm{mg} / \mathrm{kg}$, i.p.) increases the ratio of moving distance in the central zone of the open field (vehicle, $1.88 \pm 1.06 \%$; diazepam, $0.5 \mathrm{mg} / \mathrm{kg}, 6.21 \pm 1.94 \% ; F_{(2,27)}=26.94 ;{ }^{*} p<0.05 ; n=12 ; \boldsymbol{D}$ ) and reduces the ratio of moving distance in the peripheral zone of the open field (vehicle, $81.39 \pm 5.02 \%$; diazepam, $0.5 \mathrm{mg} / \mathrm{kg}, 71.20 \pm 5.75 \% ; F_{(2,27)}=$ $7.45 ;{ }^{*} p<0.05 ; n=12 ; E$ ) without changing the total moving distance (vehicle, $3746.22 \pm 1168.60 \mathrm{~cm}$; diazepam, $0.5 \mathrm{mg} / \mathrm{kg}$, $3778.29 \pm 1316.09 \mathrm{~cm} ; n=12 ; F_{(2,27)}=0.56$, not significant; $\left.\boldsymbol{F}\right)$.

stituted $12.2-17.5 \%$ and $22.0 \%$ of the total and TPH2-positive neurons in the DRL, respectively. However, other studies reported that coexistence of 5-HT/TPH2 and GABA/GAD is absent or very rare in the rat DRN: $0.1 \%$ in the entire DRN (Stamp and Semba, 1995) and 2\% in the DRL (Hioki et al., 2010). In this regard, we observed a considerable decrease in neuronal population coexpressing 5-HT and GAD67 between 4 and 8 weeks of age. Accordingly, this large difference could be attributable to the difference in age as well as detection methods and their restricted localization within the DRN.

At conventional synapses, GABA is released into the synaptic cleft by exocytosis of GABA-filled vesicles. In the present study, expression of VIAAT, which fills GABA and glycine into synaptic vesicles (McIntire et al., 1997; Aubrey et al., 2007), was not detected in 5-HT/GAD67 neurons by single-cell RT-PCR, double FISH, and immunofluorescence. This unexpected finding prompted us to hypothesize that 5-HT/GAD67 neurons might release GABA into the extracellular space via nonvesicular release. In this regard, GAT has been proposed to mediate nonvesicular GABA release by its reverse operation (Attwell et al., 1993). Indeed, GAT-1 has been shown to mediate GABA release in cultured hippocampal neurons under physiological conditions, and that contributes to keeping ambient GABA concentration high enough to mediate tonic inhibition through $\mathrm{GABA}_{\mathrm{A}}$ receptors (Wu et al., 2007). Our present observation that GAT-1 is expressed in 5-HT/GAD67 neurons suggests this possibility, which needs to be validated in future studies. If 5-HT/GAD67 neurons do conduct GABA synthesis and release, what is its role in 5-HTergic neurons? Because GATs cotransport $\mathrm{GABA}, 2 \mathrm{Na}^{+}$, and $\mathrm{Cl}^{-}$, reverse GABA transport preferably occurs if the membrane potential is made positive enough or if $\left[\mathrm{Na}^{+}\right]_{\mathrm{i}}$ rises to high enough levels. Thus, GAT-mediated GABA release is prone to occur during active firing of 5-HT/GAD67 neurons. Because GABA is a major inhibitory transmitter, it is likely that corelease of GABA in elevated activities of 5-HT/GAD67 neurons suppresses the excitability of their own and neighboring neurons. GABA is also known to exert neurotrophic effects and promote the synaptogenesis during early development (Represa and Ben-Ari, 2005). Moreover, GABA is a metabolite en route from glutamate to the tricarboxylic acid cycle. This GABA shunt pathway protects cells from injury and oxidative stress by supplying succinate and NADH and preventing accumulation of reactive oxygen intermediates (Waagepetersen et al., 1999; Lamigeon et al., 2001; Sauer et al., 2007). Therefore, the GABAergic nature of 5-HT/GAD67 neurons will be expected to provide the neurons with the ability to modulate neuronal excitability under some circumstances or to promote neuronal differentiation and survival.

5-HTergic neurons in the DRL have been reported to have active and passive intrinsic membrane properties that make them more excitable than those in the DRV (Crawford et al., 2010). In the present study, we further revealed that 5-HT/ GAD67 neurons exhibited lower input resistance and firing frequency than 5-HT neurons. Considering that the input resistance reflects both the density of the resting ion channels on the membrane and the cell size, our results suggest that 5-HT/GAD67 neurons have larger membrane surface area and more resting channels to conduct ions compared to 5-HT neurons. It can be speculated that the differences in firing patterns are likely due to distinct expression patterns of voltage-dependent ion channels, including Kv4.3 selectively expressed in the DRN (Serodio and Rudy, 1998). Kv4.3 is activated at subthreshold voltages and shows pronounced inactivation with sustained depolarization at these voltages, enabling neurons to fire rhythmically at low frequencies through a sequence of activation followed by inactivation during interspike intervals (Connor and Stevens, 1971a,b; Rush and Rinzel, 1995). Thus, although the differences in expression profiles of voltage-dependent ion channels, including Kv4.3, between 5-HT/ GAD67 and 5-HT neurons remain unknown, there are intrinsic membrane properties that make 5-HT/GAD67 neurons fire at lower frequency. 
Hale et al. (2008) reported that the exposure of rats to an OF arena markedly increases c-Fos expression in both TPHpositive and TPH-negative neurons in the DRL. In the present study, we confirmed this and further revealed that diazepam suppressed the OF stress-induced c-Fos expression at a dose that effectively lowered the anxiety level. Furthermore, PVpositive 5-HT neurons in the DRL, which are largely equivalent to 5-HT/GAD67 neurons, were more responsive to $\mathrm{OF}$ stress than PV-negative 5-HT neurons (i.e., 5-HT neurons). On the other hand, CFC stress robustly induced c-Fos expression in all DRN subdivisions examined, and this was significantly suppressed by diazepam. Considering higher plasma corticosterone concentrations induced by CFC stress than OF stress (Hirata et al., 2008; Hirata et al., 2009), the different neuronal responses between the two tests might be related to different types and intensities of stressors. While exposing animals to an $\mathrm{OF}$ arena drives the motivation of novelty-seeking behavior on one hand, it also increases the anxiety on the other hand, because of the novelty of unfamiliar environments (Gray and McNaughton, 2003; Padilla et al., 2010; Molander et al., 2011). Our observation that administration of diazepam suppressed both anxiety-related behavior and c-Fos expression in the DRL without affecting the total moving distance supports this notion. In contrast, c-Fos expression induced by OF stress in the DRD and DRV was resistant to diazepam. Because these nuclei project not only to the basolateral amygdala (Hale et al., 2008), but also to the medial prefrontal cortex and nucleus accumbens (Van Bockstaele et al., 1993), the c-Fos induction in these nuclei may be related to the cognition or novelty-seeking behaviors. Together, these findings suggest that neurons in the DRL, particularly 5-HT/GAD67 neurons, are highly sensitive to innocuous stressors, in which activation of diazepam-sensitive $\mathrm{GABA}_{\mathrm{A}}$ receptors may be involved.

Subdivisions of the DRN innervate distinct targets and receive disparate afferent inputs (Abrams et al., 2004; Lee et al., 2005, 2007; Hale et al., 2008), including 5-HTergic interactions within the DRN (Lemos et al., 2006; Kirby et al., 2007). Neurons in the DRL have been deemed to play a distinctive, crucial role in the response to stressors. Various types of stressors, including OF stress, social stress, and swim stress, along with anxiogenic drugs or reagents activates DRL neurons preferentially (Roche et al., 2003; Abrams et al., 2005; Berton et al., 2007; Hale et al., 2008; Johnson et al., 2008). 5-HTergic neurons in the ventrolateral periaqueductal gray (vlPAG), which is overlapped or embedded in the DRL, project to major sympathoexcitatory regions, the dIPAG and the RVLM, i.e., the adrenergic C1 region (Johnson et al., 2004). Microstimulation of the dlPAG in rodents and humans produces marked sympathoexcitatory responses, such as tachycardia and hypertension, thus facilitating rapid autonomic and behavioral "fight-or-flight" responses. Microstimulation of the DRL/vlPAG, by contrast, results in sympathetic inhibition (Beckett and Marsden, 1997; Underwood et al., 1999; Bago and Dean, 2001; Johnson et al., 2004). The emerging hypothesis is that neu- rons in the DRL/vlPAG are activated and help inhibit sympathetic excitation as a part of normative response to innocuous stressors (Crawford et al., 2010). This circuit is dysregulated in a rat model of panic disorder, in which decreased activation of this region accompanies excessive panic-like response to a mild stressor (Johnson et al., 2008). In this regard, 5-HT/GAD67 neurons, which constitute a unique neuronal population in the DRL with distinct neurochemical and electrophysiological properties and high responsiveness to innocuous stress, seem intriguing in stress-related physiological response and also in stress-related disorders.

\section{References}

Abrams JK, Johnson PL, Hollis JH, Lowry CA (2004) Anatomic and functional topography of the dorsal raphe nucleus. Ann NY Acad Sci 1018:46-57.

Abrams JK, Johnson PL, Hay-Schmidt A, Mikkelsen JD, Shekhar A, Lowry CA (2005) Serotonergic systems associated with arousal and vigilance behaviors following administration of anxiogenic drugs. Neuroscience 133:983-997.

Attwell D, Barbour B, Szatkowski M (1993) Nonvesicular release of neurotransmitter. Neuron 11:401-407.

Aubrey KR, Rossi FM, Ruivo R, Alboni S, Bellenchi GC, Le Goff A, Gasnier B, Supplisson S (2007) The transporters GlyT2 and VIAAT cooperate to determine the vesicular glycinergic phenotype. J Neurosci 27:6273-6281.

Bago M, Dean C (2001) Sympathoinhibition from ventrolateral periaqueductal gray mediated by 5-HT(1A) receptors in the RVLM. Am J Physiol Regul Integr Comp Physiol 280:R976-R984.

Beckett S, Marsden CA (1997) The effect of central and systemic injection of the 5-HT1A receptor agonist 8-OHDPAT and the 5-HT1A receptor antagonist WAY100635 on periaqueductal grey-induced defence behaviour. J Psychopharmacol 11:35-40.

Belin MF, Nanopoulos D, Didier M, Aguera M, Steinbusch H, Verhofstad A, Maitre M, Pujol JF (1983) Immunohistochemical evidence for the presence of gamma-aminobutyric acid and serotonin in one nerve cell. A study on the raphe nuclei of the rat using antibodies to glutamate decarboxylase and serotonin. Brain Res 275:329-339. 

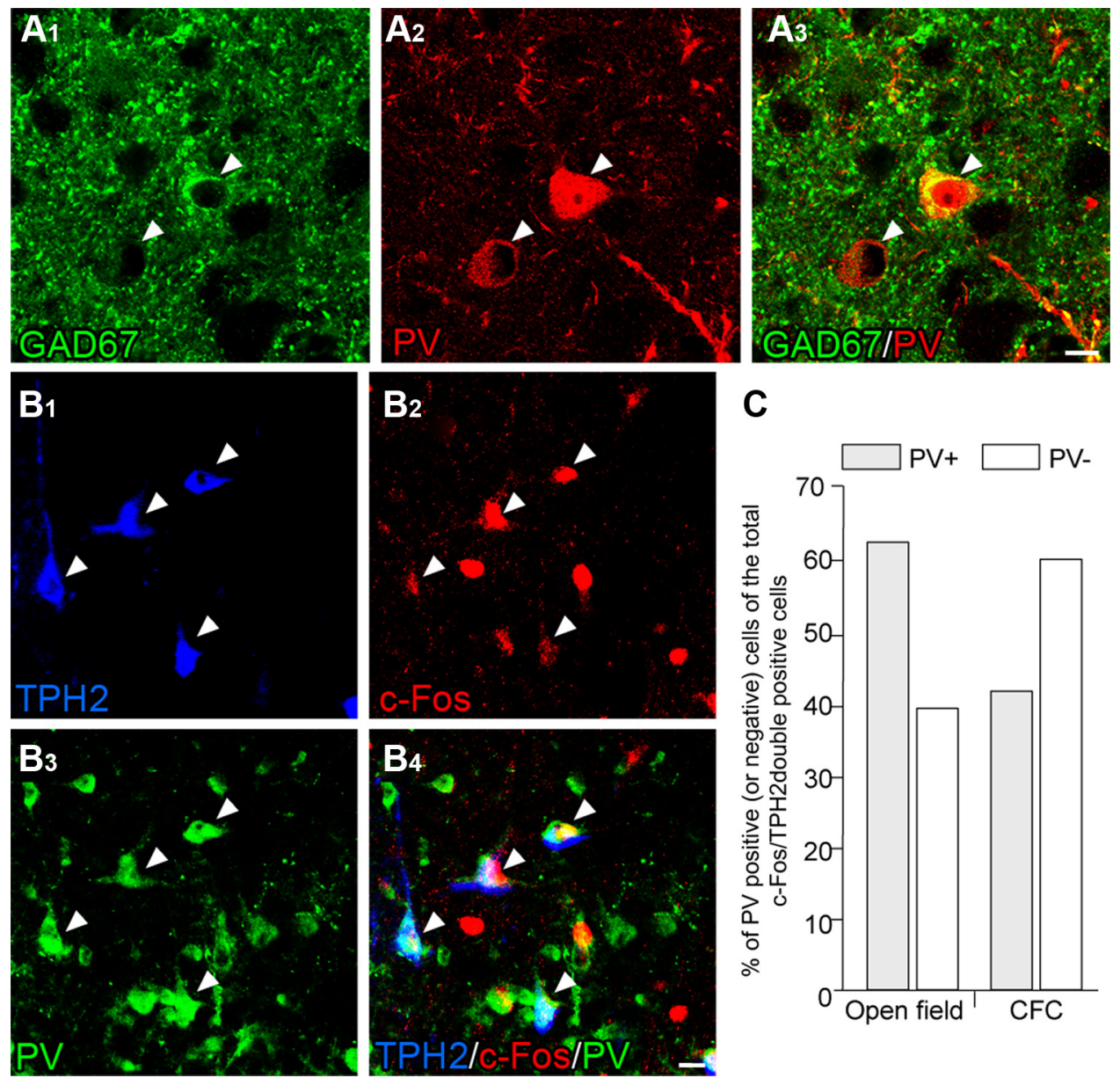

Figure 10. 5-HT/GAD67 neurons in the DRL are sensitive to OF stress. $A_{1}-A_{3}$, Double immunofluorescence for GAD67 (green) and PV (red). Note that perikarya of PV-positive cells are readily identified with strong immunoreactivity (arrowheads) and more or less coexpress GAD67. $\boldsymbol{B}_{1}-\boldsymbol{B}_{4}$, Triple immunofluorescence for c-Fos (blue), TPH2 (red), and PV (green). Arrowheads indicate c-Fos/TPH2/PV-positive cells in the DRL. C, Summary bar graphs showing the percentage of PV-positive cells in the total c-Fos/TPH2-positive cells. Scale bars: $\boldsymbol{A}_{3}$ (for $\left.\boldsymbol{A}_{1}-\boldsymbol{A}_{3}\right), \boldsymbol{B}_{\mathbf{4}}$ (for $\left.\boldsymbol{B}_{1}-\boldsymbol{B}_{4}\right), 10 \mu \mathrm{m}$.

Berton O, Covington HE 3rd, Ebner K, Tsankova NM, Carle TL, Ulery P, Bhonsle A, Barrot M, Krishnan V, Singewald GM, Singewald N, Birnbaum S, Neve RL, Nestler EJ (2007) Induction of deltaFosB in the periaqueductal gray by stress promotes active coping responses. Neuron 55:289-300

Connor JA, Stevens CF (1971a) Voltage clamp studies of a transient outward membrane current in gastropod neural somata. J Physiol 213:21-30.

Connor JA, Stevens CF (1971b) Prediction of repetitive firing behaviour from voltage clamp data on an isolated neurone soma. J Physiol 213:31-53.

Crawford LK, Craige CP, Beck SG (2010) Increased intrinsic excitability of lateral wing serotonin neurons of the dorsal raphe: a mechanism for selective activation in stress circuits. J Neurophysiol 103:2652-2663.

Fu W, Le Maitre E, Fabre V, Bernard JF, David Xu ZQ, Hokfelt T (2010) Chemical neuroanatomy of the dorsal raphe nucleus and adjacent structures of the mouse brain. J Comp Neurol 518:3464-3494.

Gallager DW, Aghajanian GK (1976) Effect of antipsychotic drugs on the firing of dorsal raphe cells. I. Role of adrenergic system. Eur J Pharmacol 39:341-355.

Gray JA, McNaughton N (2003) The neuropsychology of anxiety: an enquiry into the functions of the septo-hippocampal system, Ed 2. New York: Oxford UP.

Hale MW, Lowry CA (2011) Functional topography of midbrain and pontine serotonergic systems: implications for synaptic regulation of serotonergic circuits. Psychopharmacology 213:243-264.

Hale MW, Hay-Schmidt A, Mikkelsen JD, Poulsen B, Bouwknecht JA, Evans AK, Stamper CE, Shekhar A, Lowry CA (2008) Exposure to an openfield arena increases c-Fos expression in a subpopulation of neurons in the dorsal raphe nucleus, including neurons projecting to the basolateral amygdaloid complex. Neuroscience 157:733-748.
Hioki H, Nakamura H, Ma YF, Konno M, Hayakawa T, Nakamura KC, Fujiyama F, Kaneko T (2010) Vesicular glutamate transporter 3-expressing nonserotonergic projection neurons constitute a subregion in the rat midbrain raphe nuclei. J Comp Neurol 518:668-686,

Hirata R, Togashi H, Matsumoto M, Yamaguchi T, Izumi T, Yoshioka M (2008) Characterization of stress-induced suppression of long-term potentiation in the hippocampal CA1 field of freely moving rats. Brain Res 1226:27-32.

Hirata R, Matsumoto M, Judo C, Yamaguchi T, Izumi T, Yoshioka M, Togashi H (2009) Possible relationship between the stress-induced synaptic response and metaplasticity in the hippocampal CA1 field of freely moving rats. Synapse 63:549-556.

Itouji A, Sakai N, Tanaka C, Saito N (1996) Neuronal and glial localization of two GABA transporters (GAT1 and GAT3) in the rat cerebellum. Brain Res Mol Brain Res 37:309-316.

Izumi T, Boku S, Shinmin W, Inoue T, Konno K, Yamaguchi T, Yoshida T, Matsumoto M, Watanabe M, Koyama T, Yoshioka M (2011) Retrieval of conditioned fear activates the basolateral and intercalated nucleus of amygdala. J Neurosci Res 89:773-790.

Jacobs BL, Azmitia EC (1992) Structure and function of the brain serotonin system. Physiol Rev 72:165-229.

Johnson PL, Lightman SL, Lowry CA (2004) A functional subset of serotonergic neurons in the rat ventrolateral periaqueductal gray implicated in the inhibition of sympathoexcitation and panic. Ann N Y Acad Sci 1018:58-64.

Johnson P, Lowry C, Truitt W, Shekhar A (2008) Disruption of GABAergic tone in the dorsomedial hypothalamus attenuates responses in a subset of serotonergic neurons in the dorsal raphe nucleus following lactateinduced panic. J Psychopharmacol 22:642-652.

Kirby LG, Pan YZ, Freeman-Daniels E, Rani S, Nunan JD, Akanwa A, Beck SG 
(2007) Cellular effects of swim stress in the dorsal raphe nucleus. Psychoneuroendocrinology 32:712-723.

Lamigeon C, Bellier JP, Sacchettoni S, Rujano M, Jacquemont B (2001) Enhanced neuronal protection from oxidative stress by coculture with glutamic acid decarboxylase-expressing astrocytes. J Neurochem 77:598-606.

Lee HS, Lee BY, Waterhouse BD (2005) Retrograde study of projections from the tuberomammillary nucleus to the dorsal raphe and the locus coeruleus in the rat. Brain Res 1043:65-75.

Lee HS, Eum YJ, Jo SM, Waterhouse BD (2007) Projection patterns from the amygdaloid nuclear complex to subdivisions of the dorsal raphe nucleus in the rat. Brain Res 1143:116-125.

Lemos JC, Pan YZ, Ma X, Lamy C, Akanwa AC, Beck SG (2006) Selective 5-HT receptor inhibition of glutamatergic and GABAergic synaptic activity in the rat dorsal and median raphe. Eur J Neurosci 24:3415-3430.

Lucki I (1998) The spectrum of behaviors influenced by serotonin. Biol Psychiatry 44:151-162.

McIntire SL, Reimer RJ, Schuske K, Edwards RH, Jorgensen EM (1997) Identification and characterization of the vesicular GABA transporter. Nature 389:870-876.

Michelsen KA, Schmitz C, Steinbusch HW (2007) The dorsal raphe nucleusfrom silver stainings to a role in depression. Brain Res Rev 55:329-342.

Miura E, Fukaya M, Sato T, Sugihara K, Asano M, Yoshioka K, Watanabe M (2006) Expression and distribution of JNK/SAPK-associated scaffold protein JSAP1 in developing and adult mouse brain. J Neurochem 97:1431-1446.

Miyazaki T, Fukaya M, Shimizu H, Watanabe M (2003) Subtype switching of vesicular glutamate transporters at parallel fibre-Purkinje cell synapses in developing mouse cerebellum. Eur J Neurosci 17:2563-2572.

Molander AC, Mar A, Norbury A, Steventon S, Moreno M, Caprioli D, Theobald DE, Belin D, Everitt BJ, Robbins TW, Dalley JW (2011) High impulsivity predicting vulnerability to cocaine addiction in rats: some relationship with novelty preference but not novelty reactivity, anxiety or stress. Psychopharmacology (Berl) 215:721-731.

Morara S, Brecha NC, Marcotti W, Provini L, Rosina A (1996) Neuronal and glial localization of the GABA transporter GAT-1 in the cerebellar cortex. Neuroreport 7:2993-2996.

Nakamura M, Sato K, Fukaya M, Araishi K, Aiba A, Kano M, Watanabe M (2004) Signaling complex formation of phospholipase Cbeta4 with metabotropic glutamate receptor type lalpha and 1,4,5-trisphosphate receptor at the perisynapse and endoplasmic reticulum in the mouse brain. Eur J Neurosci 20:2929-2944.

Nanopoulos D, Belin MF, Maitre M, Vincendon G, Pujol JF (1982) Immunocytochemical evidence for the existence of GABAergic neurons in the nucleus raphe dorsalis. Possible existence of neurons containing serotonin and GABA. Brain Res 232:375-389.

Ohmura Y, Yamaguchi T, Izumi T, Matsumoto M, Yoshioka M (2008) Corticotropin releasing factor in the median raphe nucleus is involved in the retrieval of fear memory in rats. Eur J Pharmacol 584:357-360.

Ohmura Y, Izumi T, Yamaguchi T, Tsutsui-Kimura I, Yoshida T, Yoshioka M (2010) The serotonergic projection from the median raphe nucleus to the ventral hippocampus is involved in the retrieval of fear memory through the corticotropin-releasing factor type 2 receptor. Neuropsychopharmacology 35:1271-1278.
Padilla E, Shumake J, Barrett DW, Holmes G, Sheridan EC, Gonzalez-Lima F (2010) Novelty-evoked activity in open field predicts susceptibility to helpless behavior. Physiol Behav 101:746-754.

Piñeyro G, Blier P (1999) Autoregulation of serotonin neurons: role in antidepressant drug action. Pharmacol Rev 51:533-591.

Represa A, Ben-Ari Y (2005) Trophic actions of GABA on neuronal development. Trends Neurosci 28:278-283.

Roche M, Commons KG, Peoples A, Valentino RJ (2003) Circuitry underlying regulation of the serotonergic system by swim stress. J Neurosci 23:970-977.

Rush ME, Rinzel J (1995) The potassium A-current, low firing rates and rebound excitation in Hodgkin-Huxley models. Bull Math Biol 57:899-929.

Sauer SW, Kölker S, Hoffmann GF, Ten Brink HJ, Jakobs C, Gibson KM, Okun JG (2007) Enzymatic and metabolic evidence for a region specific mitochondrial dysfunction in brains of murine succinic semialdehyde dehydrogenase deficiency (Aldh5a1-/- mice). Neurochem Int 50:653-659.

Serodio P, Rudy B (1998) Differential expression of Kv4 K+ channel subunits mediating subthreshold transient $\mathrm{K}+$ (A-type) currents in rat brain. J Neurophysiol 79:1081-1091.

Somogyi J, Baude A, Omori Y, Shimizu H, El Mestikawy S, Fukaya M, Shigemoto R, Watanabe M, Somogyi P (2004) GABAergic basket cells expressing cholecystokinin contain vesicular glutamate transporter type 3 (VGLUT3) in their synaptic terminals in hippocampus and isocortex of the rat. Eur J Neurosci 19:552-569.

Stamp JA, Semba K (1995) Extent of colocalization of serotonin and GABA in the neurons of the rat raphe nuclei. Brain Res 677:39-49.

Thiébot MH, Jobert A, Soubrié P (1980) Chlordiazepoxide and GABA injected into raphé dorsalis release the conditioned behavioural suppression induced in rats by a conflict procedure without nociceptive component. Neuropharmacology 19:633-641.

Underwood MD, Arango V, Bakalian MJ, Ruggiero DA, Mann JJ (1999) Dorsal raphe nucleus serotonergic neurons innervate the rostral ventrolateral medulla in rat. Brain Res 824:45-55.

Van Bockstaele EJ, Biswas A, Pickel VM (1993) Topography of serotonin neurons in the dorsal raphe nucleus that send axon collaterals to the rat prefrontal cortex and nucleus accumbens. Brain Res 624:188-198.

Waagepetersen HS, Sonnewald U, Schousboe A (1999) The GABA paradox: multiple roles as metabolite, neurotransmitter, and neurodifferentiative agent. J Neurochem 73:1335-1342.

Wojcik SM, Katsurabayashi S, Guillemin I, Friauf E, Rosenmund C, Brose N, Rhee JS (2006) A shared vesicular carrier allows synaptic corelease of GABA and glycine. Neuron 50:575-587.

Wu Y, Wang W, Díez-Sampedro A, Richerson GB (2007) Nonvesicular inhibitory neurotransmission via reversal of the GABA transporter GAT-1. Neuron 56:851-865.

Yamasaki M, Matsui M, Watanabe M (2010) Preferential localization of muscarinic M1 receptor on dendritic shaft and spine of cortical pyramidal cells and its anatomical evidence for volume transmission. J Neurosci 30:4408-4418.

Zangrossi HJ Jr, Viana MB, Zanoveli J, Bueno C, Nogueira RL, Graeff FG (2001) Serotonergic regulation of inhibitory avoidance and one-way escape in the rat elevated T-maze. Neurosci Biobehav Rev 25:637-645. 